\title{
SEPARATION OF ORGANIC AZEOTROPIC MIXTURES BY PERVAPORATION
}

\author{
Submitted to the \\ DEPARTMENT OF ENERGY \\ Division of \\ Advanced Energy Projects \\ Office of Basic Energy Sciences
}

Final Technical Report for Grant No. DE-FG03-89ER14067

December 1991

by

Membrane Technology and Research, Inc.

1360 Willow Road, Suite 103

Menlo Park, California 94025

\author{
A Small Business \\ Richard W. Baker, Principal Investigator
}

Telephone: (415) 328-2228

PATENT STATUS: This technical report is being transmitted in advance of DOE patent clearance and no further dissemination or publication shall be made of the report without prior approval of the DOE Patent Counsel or Membrane Technology and Research, Inc.

\section{MASTER}


Table of Contents

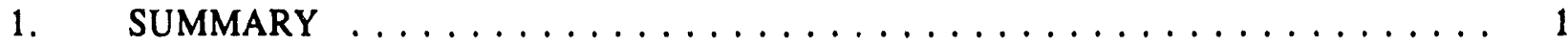

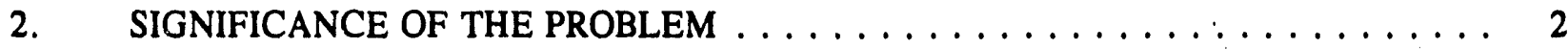

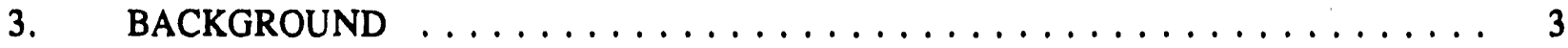

3.1 Development of Pervaporation $\ldots \ldots \ldots \ldots \ldots \ldots \ldots \ldots \ldots \ldots \ldots \ldots$

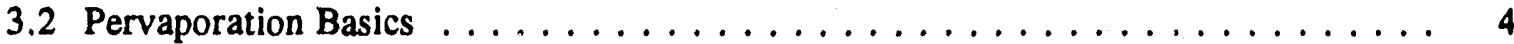

3.3 MTR Pervaporation Technology $\ldots \ldots \ldots \ldots \ldots \ldots \ldots \ldots \ldots \ldots$

4. RESEARCH OBJECTIVES $\ldots \ldots \ldots \ldots \ldots \ldots \ldots \ldots \ldots \ldots$

5. EXPERIMENTAL RESULTS $\ldots \ldots \ldots \ldots \ldots \ldots \ldots \ldots \ldots \ldots$

5.1 Selection of Azeotropic Mixtures $\ldots \ldots \ldots \ldots \ldots \ldots \ldots$

5.2 Preparation of Support Membranes $\ldots \ldots \ldots \ldots \ldots \ldots \ldots \ldots \ldots \ldots \ldots$

5.3 Preparation of Thin-Film Composite Pervaporation Membranes . . . . . . . . . . . 14

5.4 Module Development . . . . . . . . . . . . . . . . . . . . . . . . . . . . . 19

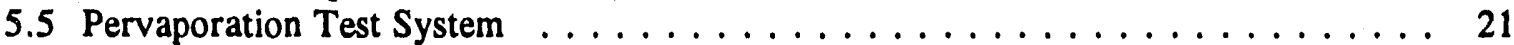

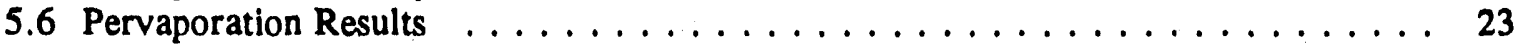

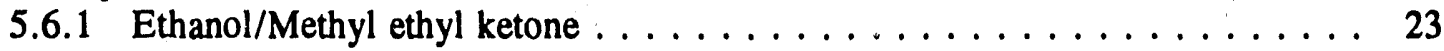

5.6 .2 Toluene/Methyl cyclohexane .................... 26

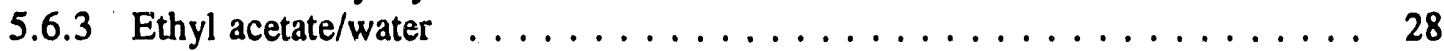

5.7 Study of Pervaporation Operating Parameters . . . . . . . . . . . . . . . . . 29

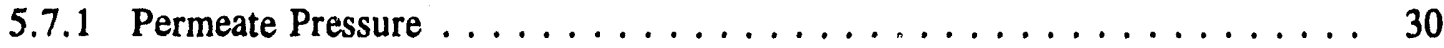

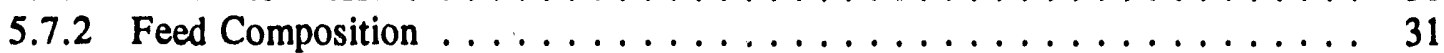

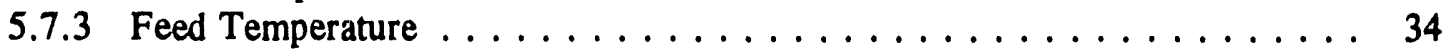

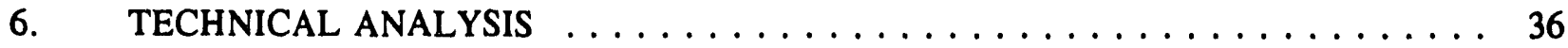

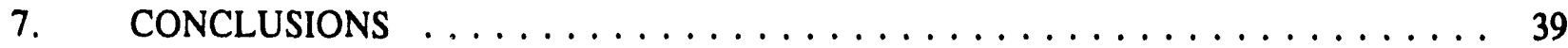

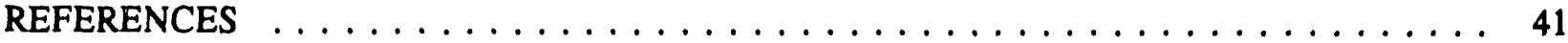

\section{DISCLAIMER}

This report was prepared as an account of work sponsored by an agency of the United States This report was prepared as an account of work sponsored by an agency of the United States employees, makes any warranty, express or implied, or assumes any legal liability or responsibility for the accuracy, completeness, or usefulness of any information, apparatus, product, or process disclosed, or represents that its use would not infringe privately uwned rights. Reference herein to any specific commercial product, process, or service by trade name, trademark, manufacturer, or otherwise does not necessarily constitute or imply its endorsement, racommendation, or favoring by the United States Government or any agency thereof. The views and opinions of authors expressed herein do not necessarily state or reflect those of the United States Government or any agency thereof. 


\section{List of Figures}

Figure 1. Effect of relative volatility on maximum efficiency for complete separation

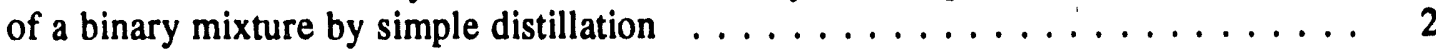

Figure 2. Schematic of the basic pervaporation process $\ldots \ldots \ldots \ldots \ldots$

Figure 3. Fraction of benzene in product vs. feed mixture composition for pervaporation at the reflux temperature of a binary benzene/cyclohexane mixture . . . . . . . 6

Figure 4. Potential configurations for pervaporation/distillation hybrid processes $\ldots \ldots \ldots$

Figure 5. Permeate concentration as a function of membrane selectivity for $50 / 50$ and $30 / 70$ azeotropic mixtures $\ldots \ldots \ldots \ldots \ldots \ldots \ldots \ldots \ldots \ldots \ldots$

Figure 6. Composite membrane structure $\ldots \ldots \ldots \ldots \ldots \ldots \ldots \ldots$

Figure 7. Schematic of MTR spiral-wound module $\ldots \ldots \ldots \ldots \ldots \ldots$

Figure 8. Schematic of MTR casting machine $\ldots \ldots \ldots \ldots \ldots \ldots \ldots$

Figure 9. Thin-film coating apparatus $\ldots \ldots \ldots \ldots \ldots \ldots \ldots \ldots$

Figure 10. Sorption of ethanol and methyl ethyl ketone by polymers $\ldots \ldots \ldots \ldots$

Figure 11. Sorption ratio as a function of mixture sorption for toluene and methyl

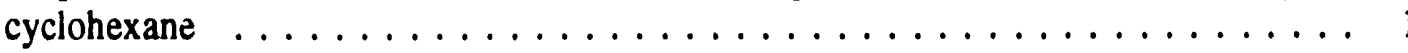

Figure 12. Schematic of the MTR module-winding procedure $\ldots \ldots \ldots \ldots \ldots$

Figure 13. Flow diagram and photograph of MTR, Inc. laboratory-scale pervaporation

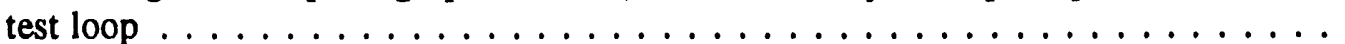

Figure 14. Pervaporation of ethanol/methyl ethyl ketone mixtures through polyamide films

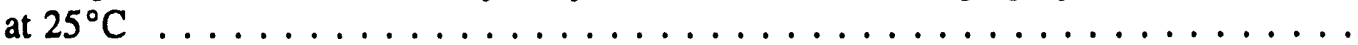

Figure 15. Pervaporation of ethanol/methyl ethyl ketone mixtures through polyamide films

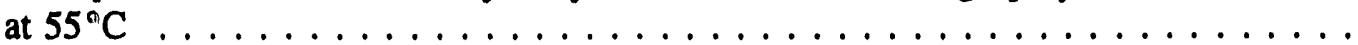

Figure 16. Permeation of toluene/methyl cyclohexane mixtures through polyetherimide/Pebax $4011 /$ cellulose acetate composite membranes at $60^{\circ} \mathrm{C} \ldots \ldots \ldots 27$

Figure 17. Permeation of ethyl acetate-water mixtures through polyamide films at $70^{\circ} \mathrm{C} \ldots \ldots$

Figure 18. Pressure-normalized fluxes of ethanol and methyl ethyl ketone through polyamide

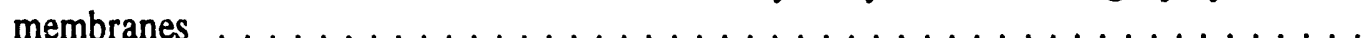


Figure 19. Membrane selectivity and total permeate flux for the permeation of ethanol-methyl ethyl ketone mixtures through polyamide membranes $\ldots \ldots \ldots \ldots \ldots \ldots$

Figure 20. Ethanol and methyl ethyl ketone flux through polyamide membranes $\ldots \ldots \ldots$

Figure 21. Experimental data and theoretical prediction for the pervaporation of ethanol/methyl ethyl ketone mixtures through polyamide membranes . . . . . . . . . . 34

Figure 22. Pressure-normalized flux of water and ethyl acetate through polyamide membranes ........................... 35

Figure 23. Calculated membrane selectivity for the pervaporation of ethyl acetate/water

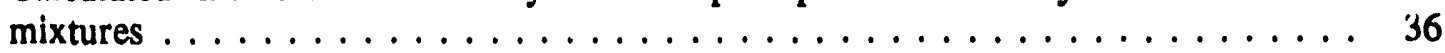

Figure 24. Process scheme for a distillation-pervaporation hybrid system used to separate ethanol $($ EtOH)/methyl ethyl ketone (MEK) mixtures . . . . . . . . . . . . . 37 
List of Tables

Table 1. Most Energy Intensive Distillations $\ldots \ldots \ldots \ldots \ldots \ldots \ldots$

Table 2. Important Binary Hydrocarbon Mixtures and Possible Entrainers . . . . . . . . 3

Table 3. Target Mixtures for Separation by Pervaporation . . . . . . . . . . . . . . 10

Table 4. Chemical Resistance of Support Membranes at $60^{\circ} \mathrm{C} \ldots \ldots \ldots \ldots$

Table 5. Sorption of Ethanol and Methyl Ethyl Ketone in Polymers . . . . . . . . . . 16

Table 6. Sorption of Toluene and Methyl Cyclohexane in Polymers . . . . . . . . . . . 18

Table 7. Module Components, Functions and Construction Materials . . . . . . . . . . . 20

Table 8. Feed Mixtures for Pervaporation $\ldots \ldots \ldots \ldots \ldots \ldots \ldots$

Table 9. Pervaporation Results for the Ethanol/Methyl Ethyl Ketone Mixture . . . . . . . . . 24

Table 10. Pervaporation Results for the Toluene/Methyl Cyclohexane Mixture . . . . . . . . . 26

Table 11. Pervaporation Results for the Ethyl Acetate/Water Mixture Separation Using Polyetherimide/Crosslinked Elvamide ${ }^{\oplus}$ Composite Membranes . . . . . . . 28

Table 12. The Effect of Permeate Pressure on the Pervaporation Separation Factor . . . . . . 30

Table 13. The Effect of Feed Ethanol Concentration on the Pervaporation Separation of Ethanol/ Methyl Ethyl Ketone Mixtures Using Elvamide ${ }^{\oplus}$ Film Membrane . . . . . . . . . . 31

Table 14. The Effect of the Feed Temperature on the Membrane Flux . . . . . . . . . 35

Table 15. Membrane Size and Energy Requirement for the Pervaporation System . . . . . . 38 


\section{SUMMARY}

This final report to the Department of Energy, Division of Advanced Energy Projects, describes work performed under contract \#DE-FG03-89ER14067, "Separation of Organic Azeotropic Mixtures by Pervaporation." The goal of the program was to demonstrate the ability of membranes to separate organic azeotropic mixtures by pervaporation.

Distillation is a commonly used separation technique in the petroleum refining and chemical processing industries. However, there are a number of potential separations involving azeotropic and close-boiling organic mixtures that cannot be separated efficiently by distillation. Pervaporation is a membrane-based process that uses selective permeation through membranes to separate liquid mixtures. Because the separation process is not affected by the relative volatility of the mixture components being separated, pervaporation can be used to separate azeotropes and close-boiling mixtures.

We selected three organic mixtures as candidates for separation by pervaporation. Two of the mixtures, ethanol/methyl ethyl ketone and ethyl acetate/water, form azeotropes. The third mixture, toluene/methyl cyclohexane was made up of close-boiling components that did not form an azeotrope. We identified suitable polymer membranes for separating these mixtures, based on the relative permeability of the riixture components. Polyamide membranes were selected to separate the ethanol/methyl ethyl ketone and ethyl acetate/water mixtures. A polyamide-polyether block copolymer membrane was used in the separation of toluene and methyl cyclohexane. A pervaporation test loop was used to test the membranes with the organic mixtures to determine the separation factor and membrane performance. We studied the effect of operating conditions including the feed temperature, feed composition and permeate pressure on the membrane performance. At the end of the program, the membranes were incorporated into chemically-resistant, spiral-wound modules. A few tests were performed with these laboratory-scale modules.

Our results showed that pervaporation membranes can be used to separate azeotropic mixtures efficiently, a result that is not achievable with simple distillation. The membranes were 5-10 times more permeable to one of the components of the mixture, concentrating it in the permeate stream. For example, the membrane was 10 times more permeable to ethanol than methyl ethyl ketone, producing a $60 \%$ ethanol permeate from an azeotropic mixture of ethanol and methyl ethyl ketone containing $18 \%$ ethanol. For the ethyl acetate/water mixture, the membranes showed a very high selectivity to water $(>300)$ and the permeate was 50-100 times enriched in water relative to the feed. The membranes had permeate fluxes on the order of $0.1-1 \mathrm{~kg} / \mathrm{m}^{2} \cdot \mathrm{h}$ in the operating range of $55-70^{\circ} \mathrm{C}$. Higher fluxes were obtained by increasing the operating temperature.

The experimental data was used to develop a process flow sheet for a pervaporation/distillation hybrid system to separate a mixture of ethanol and methyl ethyl ketone, in which the pervaporation system is used to break the ethanol/methyl ethyl ketone azeotrope. A pervaporation system to treat 100 $\mathrm{kg} / \mathrm{h}$ of a $35 \mathrm{wt} \%$ ethanol-65\% methyl ethyl ketone mixture would require $40 \mathrm{~m}^{2}$ of membrane and have a cooling requirement of $20,000 \mathrm{Btu} / \mathrm{h}$. 


\section{SIGNIFICANCE OF THE PROBLEM}

It is estimated that $40 \%$ of the total energy consumed by the chemical processing industry, amounting to 2 quads $\left(2 \times 10^{15} \mathrm{Btu}\right)$ per year, is used in distillation operations. ${ }^{1}$ The energy use is highly fragmented, as Table 1 shows. This table lists the ten most energy intensive distillations in the chemical process industry, which together consume approximately $25 \%$ of the total energy used for all distillation operations. ${ }^{2}$

Table 1. Most Energy Intensive Distillations

\begin{tabular}{|l|c|}
\hline \multicolumn{1}{|c|}{ Separation } & $\begin{array}{r}\text { Energy Consumptions, } \\
1981 \\
\text { (quads/year) }\end{array}$ \\
\hline Crude oil & 0.32 \\
Intermediate hydrocarbon liquids & 0.29 \\
Light hydrocarbons & 0.22 \\
Vacuum oil & 0.08 \\
Sour water & 0.024 \\
Ammonia/water & 0.023 \\
Styrene/ethyl benzene & 0.0115 \\
Ethylene glycol/water & 0.0109 \\
Methanol/water & 0.0107 \\
Oxygen/nitrogen & 0.0103 \\
\hline
\end{tabular}

Distillation is a particularly energy-intensive operation, when the components being separated have similar boiling points. Figure 1 is a plot of the maximum efficiency for the complete separation of a binary mixture as a function of the relative volatility of the components. ${ }^{3}$ The relative volatility is a measure of the separability of the mixture by evaporation; for azeotropic mixtyres the relative volatility is 1. As seen Figure 1, the efficiency of separation by distillation decreases as the relative volatility decreases. It is extremely difficult to separate mixtures with close-boiling components. Azeotropes cannot be separated by simple distillation.

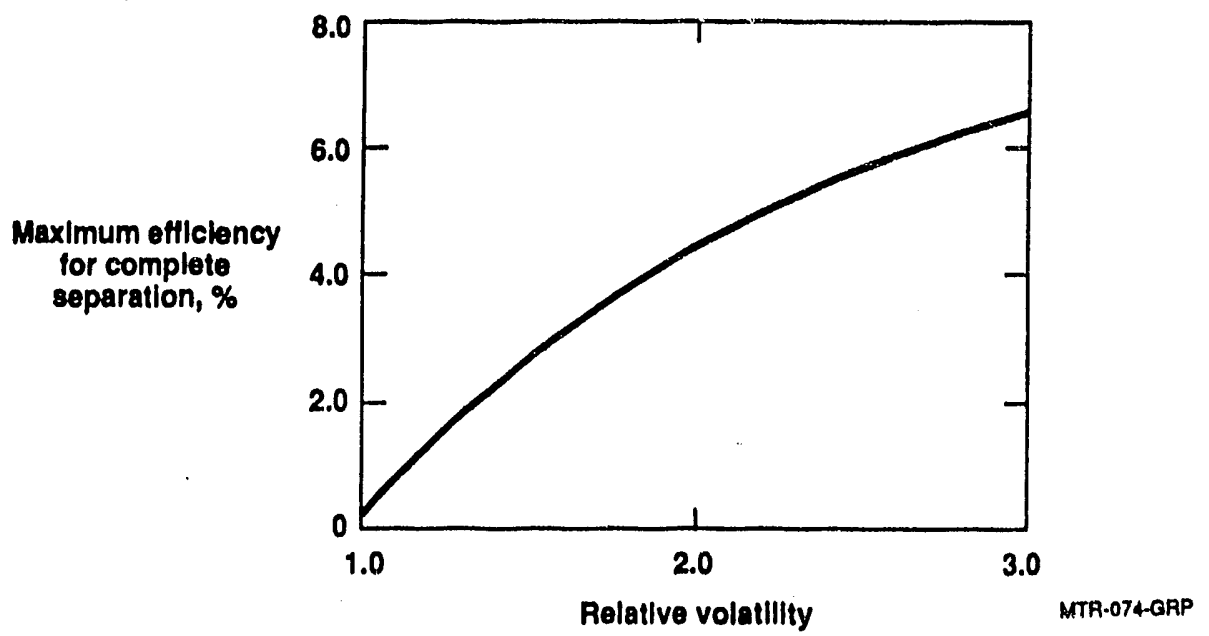

Figure 1. Effect of relative volatility on maximum efficiency for complete separation of a binary mixture by simple distillation. 
There are a number of important separations in the petroleum refining and chemical processing industries that involve azeotropic or close-boiling mixtures, some of which are listed in Table 2 . Because these separations are not amenable to simple distillation, a third component, an entrainer, is added to increase the relative volatility of the major components and break the azeotrope. The entrainers commonly used are listed in Table 2, along with mixtures being separated. These distillation separations include additional separation steps to recover the entrainer.

Table 2. Important Binary Hydrocarbon Mixtures and Possible Entrainers

\begin{tabular}{||l|c|l|c||}
\hline \multicolumn{1}{|c|}{ Hydrocarbon system } & $\begin{array}{c}\text { Relative } \\
\text { volatility }\end{array}$ & \multicolumn{1}{|c|}{$\begin{array}{c}\text { Best } \\
\text { entrainer }\end{array}$} & Relative \\
volatility
\end{tabular}

As the data in Table 2 indicate, adding an entrainer does not always result in a significant improvement in separability. In many cases there is no suitable entrainer available. Where standard distillation is unsuitable, extractive distillation, liquid/liquid separation, or other techniques must be used.

Pervaporation is a relatively new membrane process that can be applied to the separation of organic mixtures. A liquid mixture is separated by the preferential permeation of one of the components through the membrane. Because the separation is governed by the permeation characteristics of the membrane and not the relative volatility of the mixture, it is possible to separate azeotropes and closeboiling mixtures. If successfully developed, pervaporation could offer significant cost and energy savings over distillation and other separation techniques.

\section{BACKGROUND}

\subsection{Development of Pervaporation}

The origins of pervaporation can be traced to the 19th century, but the process was first studied in a systematic fashion by Binning, Lee and co-workers at American Oil in the early 1950s.5 Binning and Lee were interested in applying the process to the separation of organic mixtures. Although this work was pursued for a number of years and several patents were obtained, the process was not commercialized. The available membrane fabrication technology did not allow production of the high- 
performance membranes and modules required for a commercially competitive process. By the 1980s, however, advancements in membrane technology made it possible to prepare economically viable pervaporation systems for some separations.

Pervaporation has now been commercialized for two applications. The first application is the separation of water from 90-95\% ethanol solutions, by GFT of Hamburg, West Germany. Currently, GFT has installed more than 100 plants for this application. ${ }^{6}$ The second application is the separation of small amounts of organic compounds from contaminated waters by our company, Membrane Technology \& Research Inc. (MTR). ${ }^{7}$ Both of these processes involve separation of organics from water. This separation is relatively easy, because organic compounds and water, due to their difference in polarity, exhibit distinct membrane permeation properties. In addition, the feed solutions are relatively non-aggressive and do not chemically degrade the membrane.

No commercial systems have yet been developed for the separation of the more industrially significant organic/organic mixtures. However, current membrane technology now makes devalopment of pervaporation for these applications possible and the process is being actively researched in a number of laboratories. The first pilot-plant results for an organic-organic application, the separation of methanol from methyl tertiary butyl ether/ isobutene mixtures, were recently reported by Air Products. ${ }^{8,9}$ Texaco is also working on pervaporation for organic-organic separations.. ${ }^{10}$

The two problems that must be solved before pervaporation can be used for organic/organic separations are the development of high-flux and high-selectivity membranes and the development of membrane and module components that are chemically resistant to the organic feed solutions. Successful development of high-performance, chemically-resistant membranes and modules will have a significant impact on the chemical processing and petroleum refining industries.

\subsection{Pervaporation Basics}

A schematic of the basic pervaporation process is shown in Figure 2. In pervaporation, a liquid mixture contacts one side of a membrane; the permeate is removed as a vapor from the other side. The driving force for transport through the membrane is the difference in vapor pressure between the liquid feed solution and the permeate vapor. This vapor pressure difference can be maintained in several ways. In the laboratory a vacuum pump is usually used to draw a vacuum on the permeate side of the system. In an industrial-scale unit, the permeate vacuum is most economically generated by cooling the permeate vapor, causing it to condense. The more permeable component, which is normally the more volatile component, permeates the membrane faster than the other components and is enriched in the permeate.

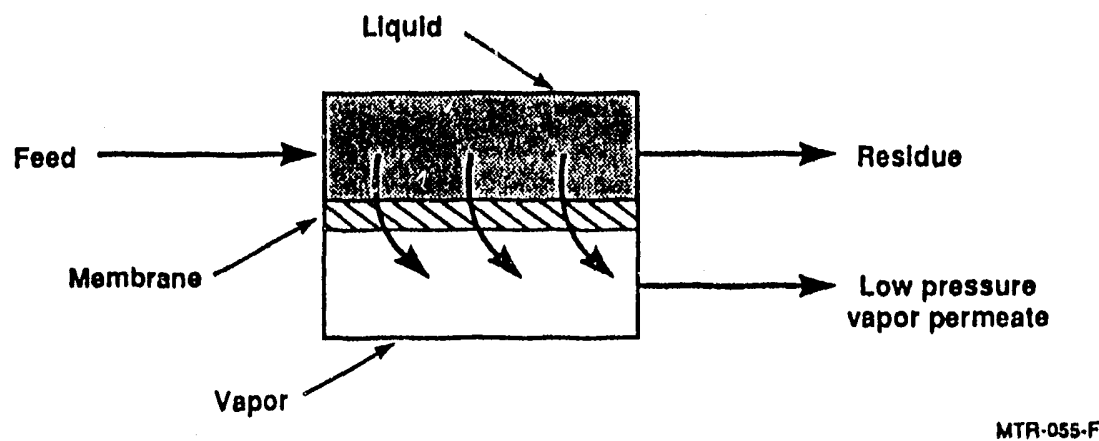

Figure 2. Schematic of the basic pervaporation process. 
Pervaporation can be modeled as a two-step process. The first step is the evaporation of the feed liquid to form a (hypothetical) saturated vapor phase on the feed side of the membrane. The second step is the permeation of this vapor through the membrane. Although no vapor phase is actually formed, this approach is simple and thermodynarnically equivalent to the physical process.

The separation, $\beta_{\text {porvap }}$, achieved by a pervaporation process can be defined in the conventional way as

$$
\beta_{\text {pervap }}=\frac{c_{i}^{\prime \prime} / c_{j}^{\prime \prime}}{c_{i}^{\prime} / c_{j}^{\prime}} \text {, }
$$

where $c_{i}{ }^{\prime}$ and $c_{j}{ }^{\prime}$ are the molar concentrationis of components $i$ and $j$ on the feed liquid side and $c^{\prime \prime}{ }_{1}$ and $c^{\prime \prime}{ }_{j}$ are the concentrations of components $i$ and $j$ on the permeate side of the membrane.

The overall separation factor is the product of the separation factors for each of the sub-processes. For a binary mixture, the separation factor in the evaporation step is actually the relative volatility of the two components. The separation factor in the permeation step is a function of the membrane selectivity and the vapor pressures on either side of the membrane. The membrane selectivity is the ratio of the permeability coefficients of the two components in the membrane and is normally a constant (at constant temperature). However, this study showed the permeability coefficient can also be a function of the liquid composition if excessive liquid sorption into the polymer membrane leads to swelling of the polymer. When the difference between the feed- and permeate-side vapor pressures is large, the separation factor for the permeation step is equal to the membrane selectivity.

To achieve a good overall separation, both the evaporation separation factor and the membrane permeation separation factor should be large. Therefore, pervaporation is best suited for the removal of volatile components from relatively non-volatile components. However, if the membrane permeation separation factor is large enough, the overall separation will be good even when the separation due to evaporation is very small, as in the case of near-azeotropic mixtures.

The degree of separation of a binary mixture is, therefore, a function of the relative volatility of the components, the membrane selectivity and the operating conditions. For azeotropic or close-boiling mixtures, the relative volatility is very close to 1 , so separation by simple distillation is not viable. However, if the membrane permeation selectivity is much greater than 1 , a significant separation is possible using pervaporation. This is illustrated in Figure 3, which shows a plot of the pervaporation separation of benzene/cyclohexane mixtures using a $20-\mu \mathrm{m}$-thick crosslinked membrane. ${ }^{11}$ The vaporliquid equilibria for the mixtures are also presented. The benzene/cyclohexane mixture forms an azeotrope at approximately $50 \%$ benzene. A typical distillation stage would be unable to separate a feed stream of this composition. However, pervaporation treatment of this mixture produces a vapor permeate containing more than $90 \%$ benzene. This example illustrates the advantages of pervaporation over simple distillation for separating azeotropes and close-boiling mixtures. 


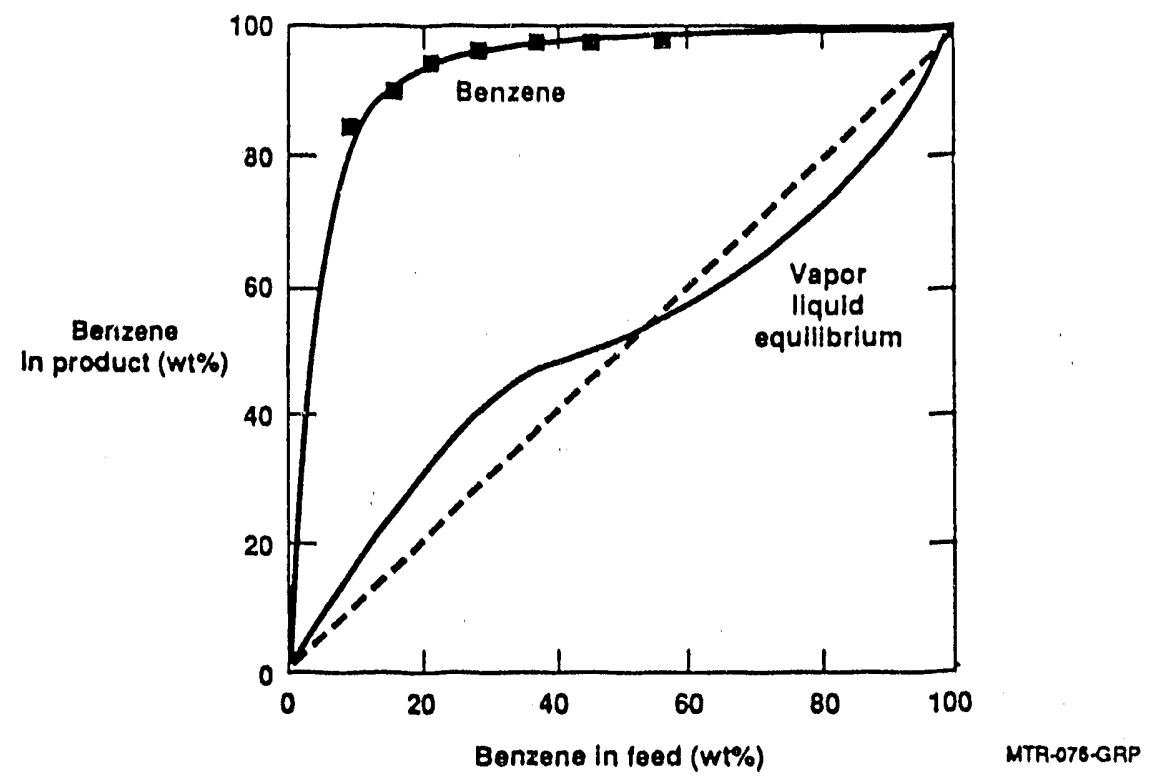

Figure 3. Fraction of benzene in product vs. feed mixture composition for pervaporation at the reflux temperature of a binary benzene/cyclohexane mixture. A $20-\mu \mathrm{m}$-thick crosslinked membrane was used."

Pervaporation is most efficient when used in conjunction with distillation in a hybrid process. The two main applications of pervaporation-distillation hybrid processes are in breaking azeotropes and in removing a single-component, high-purity side stream from a multicomponent distillation separation. Figure 4 shows some potential pervaporation-distillation combinations. Figure 4(a) combines pervaporation with distillation to break an azeotrope that is concentrated in one component $(>90 \%)$. This approach is used in the production of high-purity ethanol. Ethanol/water azeotrope from the top of the distillation column is fed to a pervaporation unit where the water is removed as the permeate and returned to the column as reflux.

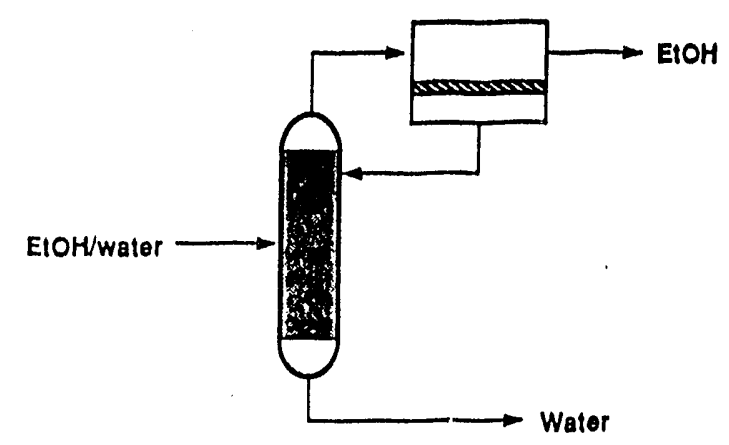

(a)

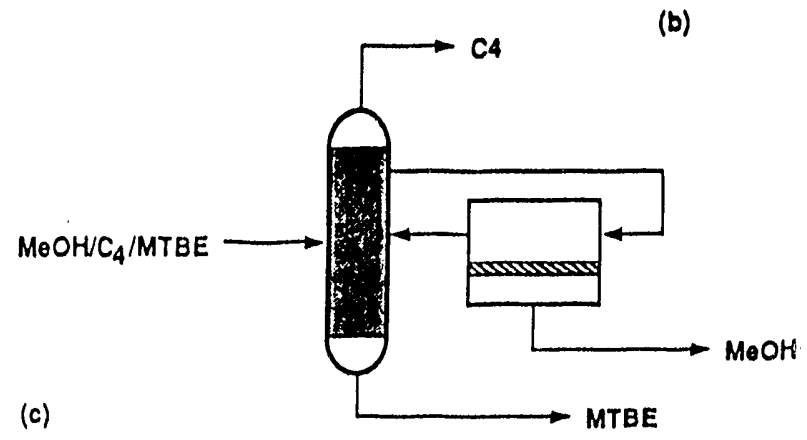

ABB Azootropo

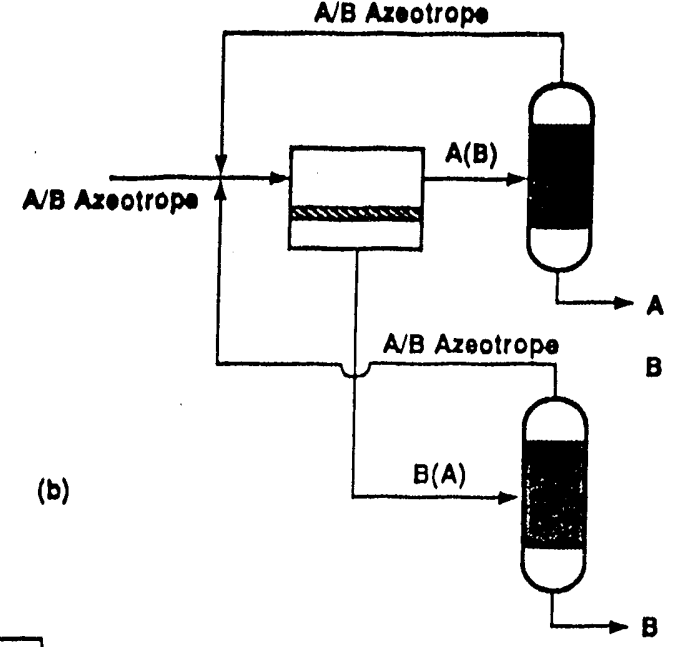

Figure 4. Potential configurations for pervaporation/distillation hybrid processes. 
Figure 4(b) illustrates the use of pervaporation with two distillation columns to break binary azeotropes that contain appreciable concentrations of both components $(20: 80$ to 80:20). The feed $(A+B)$ is supplied at the azeotropic composition and is split into two streams by the pervaporation unit. The stream rich in the more volatile component (B) is fed to a distillation column that produces a pure bottom product and an azeotropic top stream, which is recycled to the pervaporation unit. Similarly, the other distillation column treats a stream rich in the low volatile component (A) to produce a pure product stream and an azeotropic mixture that is returned to the pervaporation unit.

Pervaporation can also be used to unload a distillation column, thereby reducing energy consumption and operating cost and increasing throughput. The example presented in Figure 4(c) is for the recovery of pure methanol by pervaporation of a side stream from a column that separates a methanol/ isobutene/ methyl tertiary butyl ether feed mixture. ${ }^{10}$

Pervaporation has great potential as a process for breaking azeotropes. Even modest permeation selectivities can result in a significant separation, as illustrated in Figure 5, a plot of the permeate concentration vs. membrane selectivity for two different azeotropic feed mixtures (50:50 and 30:70).

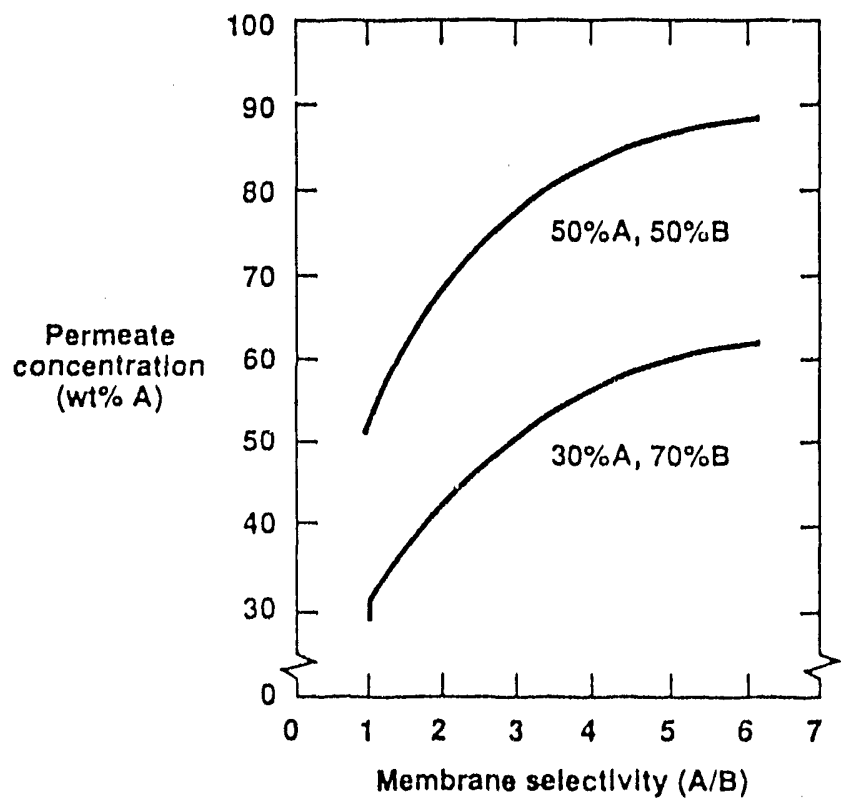

MTA.075-GAP

Figure 5. Permeate concentration as a function of membrane selectivity for 50/50 and 30/70 azeotropic mixtures.

In the calculations for Figure 5, it was assumed that half the feed solution permeates the membrane and half remains as the residue. This is called a $50 \%$ stage-cut, the stage-cut being defined as the fraction of the feed that passes through the membrane. One key conclusion to be drawn from Figure 5 is that very useful separations can be achieved even when the membrane selectivity is relatively low, of the order 4 to 8 . 


\subsection{MTR Pervaporation Technology}

MTR has been developing pervaporation technology for the past eight years. The company's early work on the removal of organic solvents from dilute aqueous streams was sponsored by the Department of Energy, Office of Advanced Energy Projects. Through further government agency awards and contracts with private business, we are bringing this application of pervaporation to commercialization of small systems.

The basis of MTR's separation technology is our ability to produce multi-layer compusite polymer mernbranes. The multilayer membrane structure, shown schematically in Figure 6, consists of a tough, open microporous polymer layer that provides strength, and an ultrathin dense polymer coating that is responsible for the separation properties. The company has developed the technology to produce these membranes, defect-free, in rolls 40 inches wide and $100-200$ yards long.

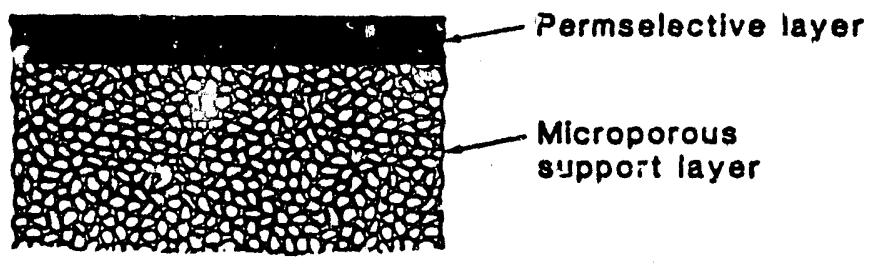

Figure 6. Composite inembrane structure.

The membranes are fabricated into spiral-wound modules of the type illustrated in Figure 7. During operation, feed liquid enters the module and flows between the memorane leaves. The permeate fraction spirals inward to a central permeate collection pipe. The remainder of the feed flows across the membrane surface and exits as the residue. The membrane modules can be connected in a series or parallel flow arrangement to meet the capacity and separation requirements of any particular separation.

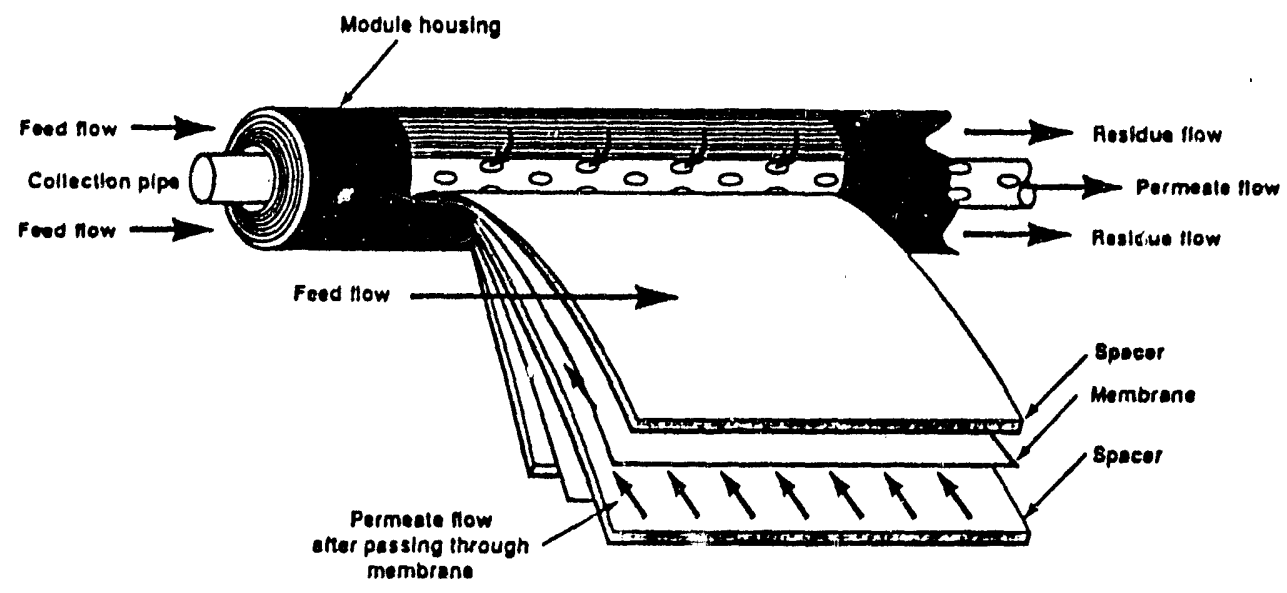

Figure 7. Schematic of MTR spiral-wound module. 


\section{RESEARCH OBJECTIVES}

The overall objective of this program was to demonstrate the ability of composite membrane modules to separate organic/organic solvent mixtures. The program addressed three major experimental tasks:

1) the preparation of high-performance, organic-resistant membranes;

2) the preparation of defect-free, organic-resistant laboratory-scale membrane modules; and

3) the evaluation of these modules in a laboratory test system.

All of the tasks were completed and the objective of separating of organic/organic azeotropic mixtures was successfully achieved.

We identified three types of azeotropic mix ures as important separations in the petroleum refining and chemical processing industries. The tiree systems studied were ethanol/methyl ethyl ketone, representing alcohol/ketone separations, toluene/methyl cyclohexane, representing aromatic/aliphatic separations, and ethyl acetate/water, representing organic/water azeotropic separations.

The next step was to develop microporous support membranes with a high degree of chemical resistance, able to tolerate hot feed solutions without swelling or failure. Concurrently with our selection of the support membranes we identified suitable polymers for use as permselective materials. We developed a selective sorption-based screening test for identifying promising polymers that would separate the feed mixtures chosen for the study. The permselective polymers were combined with the sl'oport membranes to form high-performance, thin-film composite membranes.

The composite membranes we:e formed into spiral-wound modules which were designed to have high resistance to the hot feed mixtures. We screened a number of glues to find a suitable glue for sealing membrane envelopes. New module fittings were áesigned to replace conventional fittings with poor chemical resistance.

We designed and constructed a laboratory-scale pervaporation test system to test stamps of flat sheet membrane, as well as spiral-wound modules containing up to $1 \mathrm{~m}^{2}$ of membrane area. Membranes and modules were tested in this systern using the three model organic mixtures. We determined the effect of operating conditions, including the feed temperature, permeate pressure and feed concentration, on the system performance. The results of the membrane and module development and the pervaporation tests are described in Section 5.

\section{EXPERIMENTAL RESULTS AND DISCUSSION}

\subsection{Selection of Azeotropic Mixtures}

The first step in the program was to select candidate azeotropic mixtures for separation. We identified the three broad sets of azeotropic or close-boiling mixtures listed in Table 3. The three groups include a large number of the azeotropic mixtures that are separated in the petroleum refining and 
chemical industries. We selected one representative mixture from each group and identified potential pervaporation membranes for each model separation.

The first group of mixtures consists of moderately polar, hydrophilic compounds, including combinations of aliphatic alcohols, ketones, esters and organic acids. Such mixtures are formed as intermediates in chemical synthesis, e.g. the manufacture of acetic acid or the synthesis of methyl ethyl ketone from n-butylene. The representative mixture selected for this group was ethanol/methyl ethyl ketone, which forms an azeotrope containing $18 \mathrm{wt} \%$ ethanol at $25^{\circ} \mathrm{C}$ and $29 \mathrm{wt} \%$ ethanol at $55^{\circ} \mathrm{C}$.

Table 3. Target Mixtures for Separation by Pervaporation

\begin{tabular}{|c|c|}
\hline Mixtures & Potential Membrane Materials \\
\hline $\begin{array}{l}\text { Polar hydrophilic mixtures } \\
\text { Ethanol/methyl ethyl ketone } \\
\text { Butanol/methyl ethyl ketone } \\
\text { Methanol/acetonitrile } \\
\text { Ethanol/methyl acetate } \\
\text { Ethyl acetate/ethanol }\end{array}$ & $\begin{array}{l}\text { Polyamides, polyamide-polyether block } \\
\text { copolymers and ion-exchange polymers }\end{array}$ \\
\hline $\begin{array}{l}\text { Hydrophobic-hydrophobic organic mixtures } \\
\text { Toluene/methyl cyclohexane } \\
\text { Benzene/cyclohexane } \\
\text { p-Xylene/m-xylene } \\
\text { Ethyl benzene/p-xylene } \\
\text { Ethyl benzene/styrene } \\
\text { Toluene/ethyl benzene }\end{array}$ & $\begin{array}{l}\text { Polyurethanes and polyamide-polyether } \\
\text { copolymers }\end{array}$ \\
\hline $\begin{array}{l}\text { Dehydration of polar solvents } \\
\text { Ethyl acetate } \\
\text { Acetone } \\
\text { Methyl ethyl ketone } \\
\text { Butanol } \\
\text { Methylene chloride }\end{array}$ & $\begin{array}{l}\text { Polyamides, ion-exchange polymers and } \\
\text { polyamide-polyether block copolymers }\end{array}$ \\
\hline
\end{tabular}

The second group of mixtures is made up of hydrophobic organic compounds, primarily aromatic and cyclo-aliphatic hydrocarbons. The separation of such mixtures is a widespread operation in the petroleum refining industry. Examples are the separation of ethyl benzene from styrene, one of the largest distillation operations in the petrochemical industry, and the difficult separation of xylene isomers, that requires a combination of crystallization and distillation. We selected the close-boiling mixture of toluene and methyl cyclohexane as the model system. This combination of aromatic and cyclo-aliphatic compounds is a good representative of the other mixtures in the group. 
The third group represents a common separation in the manufacture of alcohols, ketones, esters and organic acids, nanely, the removal of small quantities of water. The water is residue from the chemical synthesis steps or is added as an entrainer to break an organic/organic azeotrope. Solvent dehydration is not a trivial operation when the organic component is polar and moderately hydrophilic, and forms an azeotrope with water. A very efficient separation process is necessary so that the solvent is completely dry and the resulting aqueous stream is suitable for immediate discharge into the process sewer. Pervaporation has already been demonstrated as a viable process for dehydrating ethanol, eliminating the need for azeotropic distillation; membranes with very high selectivity to water over ethanol have been described in the literature. The dehydration of more aggressive solvents by pervaporation is an area of continuing study, in part because of the need for solvent-resistant membranes. We selected the ethyl acetate/water system as a model for studying the breaking of concentrated organic/water azeotropes. This system forms a heterogenous azeotrope containing 94 wt\% ethy! acetate at $70^{\circ} \mathrm{C}$.

The model systems represent three classes of mixtures and also three types of vapor-liquid equilibria. The ethanol/methyl ethyl ketone system forms a minimum-boiling azeotrope and the ethyl acetate/water system forms a heterogenous minimum-boiling azeotrope. The toluene/ methyl cyclohexane system is a close-boiling mixture, representing systems that do not form azeotropes but nevertheless are difficult to separate by distillation.

\subsection{Preparation of Support Membranes}

At MTR the composite membranes illustrated in Figure 6 are prepared in a two-step process. The first step is the deposition of a microporous support membrane on a polyester fabric; in the second step, the support membrane is coated with the thin, permselective layer.

The support layer is required because the permselective layer is too thin to be deposited directly onto the polyester fabric. Although the thin permselective layer is responsible for the separation, the quality of the support membrane has a significant impact on membrane performance and selectivity. The average pore diameter, membrane porosity and chemical resistance of the support are critical parameters for producing a high flux, high selectivity composite membrane.

The casting machine used to prepare the microporous membrane is shown in Figure 8. The casting solution, consisting of the polymer in a water-miscible solvent, is doctored onto a moving belt of polyester fabric. The belt passes into a water bath which precipitates the polymer to form the support membrane. The belt is then collected on a take-up roll, after which the membrane is washed overnight to remove any remaining solvent and dried. We used a 12-inch-wide casting machine to prepare membrane for laboratory test modules and a 40-inch-wite casting machine to prepare membrane for full sized modules. Suppor membranes were prepired from the polymers polysulfone (suitable for alcohol mixtures), polyamide (for halogenated organics), nolyetheramide (suitable for hydrocarbons and aromatics), and polyacrylonitrile-methacrylate-butadiene. 


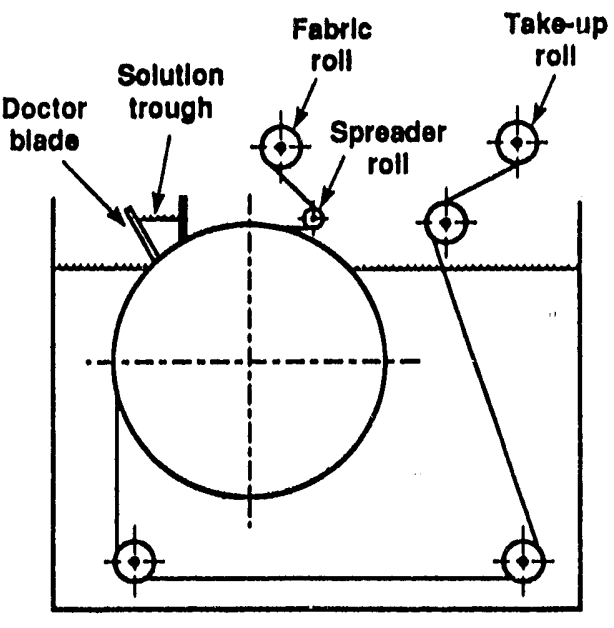

Do4.F

Figure 8. Schematic of MTR casting machine.

The materials used for support membranes are engineering polymers such as polysulfones, polyimides and polyamides. The challenge was to identify a polymer material that dissolved in a suitable processing solvent but was also resistant to attack by the organic compounds in the hot mixture to be separated.

In some cases, potential membrane materials were eliminated on the basis of chemical resistance data supplied by the polymer manufacturer, but even materials claimed to withstand the attack of the feed mixture needed further testing. The support membrane is a highly porous structure with very fine pores. Even moderate swelling of the polymer can result in damage to this structure and a decrease in the performance of the composite membrane. No single polymer can provide a wide spectrum of chemical resistance. Our approach was to prepare a number of microporous support membranes from polymers that are resistant to specific solvent groups, resulting in support membranes that are optimal for particular separations.

The support membranes were evaluated for their resistance to six organic chemicals, typical of the major groups of chemicals used or produced by the chemical processing industry:

Cyclohexane:

Toluene:

1-Butanol:

Methyl ethyl ketone:

Ethyl acetate:

1,1,2-Trichloroethane: cyclic aliphatic hydrocarbon aromatic hydrocarbon alcohol ketone ester halogenated hydrocarbon

Samples of the membrane were immersed in the organic liquid at $60^{\circ} \mathrm{C}$ for periods of up to 5 days. The samples were monitored at 24 hour intervals to determine surface crazing, swelling and dissolution effects. The air permeability of the membranes before and after exposure to the organics were compared, to determine the effect on the membrane pore structure.

The effect of exposing the membrane to the test chemicals is presented in Table 4. 
Table 4. Chemical Resistance of Support Membranes at $60^{\circ} \mathrm{C}$

\begin{tabular}{|c|c|c|c|c|c|c|}
\hline Membrane & Toluene & Cyclohexane & 1-Butanol & $\begin{array}{c}\text { Methyl ethyl } \\
\text { ketone }\end{array}$ & Ethyl acetate & $\begin{array}{c}\text { Trichloro- } \\
\text { ethane }\end{array}$ \\
\hline Polysulfone & $\begin{array}{l}\text { Dissolved } \\
(24 \mathrm{~h})\end{array}$ & $\begin{array}{l}\text { Stable } \\
(120 \mathrm{~h})\end{array}$ & $\begin{array}{l}\text { Stable } \\
(120 \mathrm{~h})\end{array}$ & $\begin{array}{l}\text { Dissolved } \\
(24 \mathrm{~h})\end{array}$ & $\begin{array}{l}\text { Dissolved } \\
(24 \mathrm{~h})\end{array}$ & Unstable \\
\hline Polyamide & $\begin{array}{l}\text { Stable } \\
(120 \mathrm{~h})\end{array}$ & $\begin{array}{l}\text { Stable } \\
(120 \mathrm{~h})\end{array}$ & $\begin{array}{l}\text { Dissolved } \\
(24 \mathrm{~h})\end{array}$ & Dissolved & $\begin{array}{l}\text { Stable } \\
(120 \mathrm{~h})\end{array}$ & $\begin{array}{l}\text { Stable } \\
(120 \mathrm{~h})\end{array}$ \\
\hline $\begin{array}{l}\text { Polyether- } \\
\text { imide }\end{array}$ & $\begin{array}{l}\text { Stable after } \\
48 \mathrm{~h} \text {; surface } \\
\text { crazing \& } \\
\text { pitting } \\
(120 \mathrm{~h})\end{array}$ & $\begin{array}{l}\text { Stable } \\
(120 \mathrm{~h})\end{array}$ & $\begin{array}{l}\text { Marginal; } \\
\text { swelling, } \\
\text { meinbrane } \\
\text { flux decreases } \\
50 \text {-fold (120 } \\
\text { h) }\end{array}$ & $\begin{array}{l}\text { Stable } \\
(120 \mathrm{~h})\end{array}$ & $\begin{array}{l}\text { Appeared } \\
\text { stable, but } \\
\text { membrane } \\
\text { flux decrease } \\
10 \text { - to } 20 \text {-fold }\end{array}$ & Unstable \\
\hline $\begin{array}{l}\text { Polyacryl- } \\
\text { onitrile } \\
\text { methacrylate- } \\
\text { butadiene } \\
\text { copoly'mer }\end{array}$ & $\begin{array}{l}\text { Stable } \\
(120 \mathrm{~h})\end{array}$ & $\begin{array}{l}\text { Stable } \\
(120 \mathrm{~h})\end{array}$ & $\begin{array}{l}\text { Stable } \\
(120 \mathrm{~h})\end{array}$ & $\begin{array}{l}\text { Dissolved } \\
(120 \mathrm{~h})\end{array}$ & $\begin{array}{l}\text { Stable } \\
(120 \mathrm{~h})\end{array}$ & $\begin{array}{l}\text { Membrane } \\
\text { destroyed } \\
(120 \mathrm{~h})\end{array}$ \\
\hline $\begin{array}{l}\text { Polypro- } \\
\text { pylene }^{1}\end{array}$ & Stable & Stable & Stable & Stable & Stable & Swells \\
\hline
\end{tabular}

'Data from manufacturers specifications

The polysulfone membrane was unaffected by exposure to cyclohexane or 1-butanol but dissolved in toluene, methyl ethyl ketone and ethyl acetate. The polymer is known to be soluble in halogenated organic solvents so it was not exposed to 1,1,2-trichloroethane.

The polyamide membrane has good resistance to cyclohexane, toluene, ethyl acetate and 1,1,2trichloroethane but dissolved in butanol and methyl ethyl ketone. This behavior is typical of amorphous polyamide materials that have good chemical resistance in general but are not stable in the presence of alcohols or ketones.

The polyetherimide membrane was not dissolved by any of the solvents in which it was tested. However, ethyl acetate and butanol reduced the air permeability of the membrane 20 - to 100 -fold after five days exposure at $60^{\circ} \mathrm{C}$. This was due to the swelling of the polymer leading to constriction and collapse of some of the pores in the membrane. The membrane was stable to short-term exposure to toluene, but after 120 hours, the surface of the membrane showed considerable crazing and pitting. Polyetherimide membranes are known to be soluble in halogenated solvents so our sample was not tested with 1,1,2-trichloroethane. 
The polyacrylonitrile-methacrylate-butadiene copolymer membranes were not affected by exposure to cyclohexane, toluene, 1-butanol and ethyl acetate but methyl ethyl ketone and 1,1,2-trichloroethane caused severe damage to the membrane structure.

We also considered polypropylene-based commercial membranes/porous films (Celgard ${ }^{\oplus}$, Hoechst-Celanese Corp.). Manufacturers specifications note that these membranes are stable in all of our test solvents except for 1,1,2-trichloroethane, which would swell the membrane. Although these membranes have the best chemical resistance of all the support materials considered, they are symmetric, with uniform cylindrical pores. Our regular support membranes have asymmetric, cone-shaped pores with the narrow openings on the surface that supports the selective layer. This allows high flux through the membrane, while providing a smooth surface suitable for depositing the selective layer. Polypropylene support membranes with fine pores are good substrates for the deposition of thin film coatings but the resistance to flow through the pores is large and possibly rate-limiting. Membranes with larger pores have higher fluxes but are very difficult to coat with thin defect-free coatings.

Our results indicated that polyetherimide membranes would be the siost versatile support membranes, suitable for hydrocarbon, alcohol and ketone mixtures. Polyamide membranes would be best for separations involving chlorinated organic solvents and polysulfone and polyacrylonitrile-methacrylatebutadiene copolymer membranes are only suitable for separations involving alcohols and aliphatic hydrocarbons.

\subsection{Preparation of Thin-Film Composite Pervaporation Membranes}

We coated the support membranes with thin films of permselective polymer to form composite membranes. The apparatus used to apply the permselective layer to the support membrane is shown in Figure 9. The microporous membrane from a feed roll passes through the coating station, through a drying oven, and is wound up on a product roll. The dip-coating tank contains a dilute solution of the polymer and coats the traveling microporous membrane with a liquid layer 50 - to $100-\mu \mathrm{m}$ thick. After evaporation of the solvent, a polymer film $0.5-$ to $1-\mu \mathrm{m}$ thick is left on the membrane.

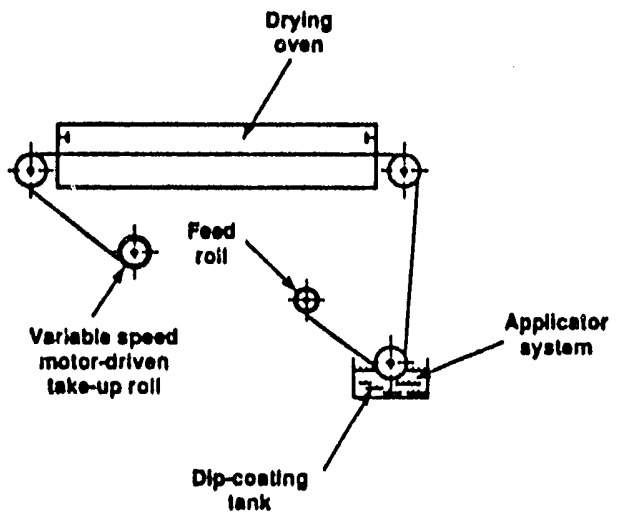

Figure 9. Thin-film coating apparatus. 
We routinely test our composite membranes by measuring the nitrogen and oxygen gas fluxes and comparing the oxygen/nitrogen permeation selectivity with the intrinsic value for the permselective material. Membrane defects such as pin-holes or cracks result in flow around the permselective barrier and a loss of selectivity. Defect-free thin-film composite membranes have the same oxygen/nitrogen selectivity as the intrinsic value for the polymer. The pervaporation membranes prepared in this project had relatively thick permselective layers and very low fluxes and consequently the selectivity could not be estimated accurately. Therefore we considered membranes with a gas flux less than $1 \times 10^{-6}$ $\mathrm{cm}^{3}(\mathrm{STP}) / \mathrm{cm}^{2}$.s.cmHg to be defect-free.

The permselective material is chosen on the basis of the permeation selectivity characteristics of the polymer for the components of the mixture. The permeability of a species in a polymer membrane is determined by the amount of that species sorbed in the membrane and the diffusivity of the sorbed species. The permeability coefficient $P_{i}$ is written as the product of the diffusion coefficient $D_{i}$ and the sorption coefficient $S_{i}$ :

$$
P_{i}=D_{i} S_{i}
$$

The membrane selectivity, $\alpha_{j}^{\prime}$, can be expressed as the product of the diffusion selectivity $\left(D_{i} / D_{j}\right)$ and the sorption selectivity $\left(S_{\mathrm{l}} / S_{\mathrm{j}}\right)$ :

$$
\alpha_{j}^{\prime}=\frac{P_{i}}{P_{j}}=\left(\frac{D_{i}}{D_{j}}\right) \cdot\left(\frac{S_{i}}{S_{j}}\right) \text {. }
$$

The diffusion selectivity for most organic/organic pervaporation separations will not be significant because the species being separated are of similar size and molecular weight and will have equivalent diffusion coefficients. Therefore, the permeation selectivity of the membrane is primarily a function of the sorption selertivity. We chose the relative sorption of the components of the feed mixture into the membrane as an indicator of the sorption selectivity.

A procedure was developed to screen potential membrane materials on the basis of sorption selestivity for the organi; liquids of interest. Samples of the polymers, in pellet or film form, were immersed in the organic iiquid for up to five days at $60^{\circ} \mathrm{C}$. The sample was weighed before and after immersion. It was then dried in a warm vacuum oven to remove any sorbed liquid and weighed. From these measurements we calculated the fraction of the sample that dissolved, as well as the equilibrium sorption uptake of liquid. For a given mixture organic/inorganic we measured the sorption of the individual components as well as the sorption of the mixture. The sorption ratio was defined as the ratio of the sorption of the pure components of the mixture in the polymer, e.g. for the ethanol/methyl ethyl ketone mixture, the sorption ratio is the ratio of the sorption of pure ethanol in the polymer to the sorption of pure methyl ethyl ketone. Sorption data for each polymer are presented in Table 5 for the ethanol/methyl ethyl ketone mixture. Figure 10 is a plot of the sorption ratio for ethanol/methyl ethyl ketone against the sorption of a near-azeotropic feed mixture (18.6 wt\% ethanol/71.4 wt\% methyl ethyl ketone). 
Table 5. Sorption of Ethanol and Methyl Ethyl Ketone in Polymers

\begin{tabular}{|c|c|c|c|c|}
\hline \multirow[b]{2}{*}{ Polymer } & \multicolumn{3}{|c|}{ Sorption (liquid/100 g polymer) } & \multirow{2}{*}{$\begin{array}{l}\text { Sorption } \\
\text { ratio } \\
(\mathrm{EtOH} / \mathrm{MEK})\end{array}$} \\
\hline & $\begin{array}{l}18.6 \% \text { ethanol } \\
81.4 \% \mathrm{MEK}\end{array}$ & $\begin{array}{l}\text { Pure } \\
\text { ethanol }\end{array}$ & $\begin{array}{l}\text { Pure } \\
\text { MEK }\end{array}$ & \\
\hline $\begin{array}{l}\text { Elvamide } 8061 \\
\text { (polyamide) }\end{array}$ & 8.6 & 30 & 2 & 15 \\
\hline $\begin{array}{l}\text { Vestamid } \\
\text { E-55-M53 } \\
\text { (polyamide- } \\
\text { polyether block } \\
\text { copolymer) }\end{array}$ & 16 & 16 & 16 & 1 \\
\hline $\begin{array}{l}\text { Vestamid } \\
\text { E-62-M53 }\end{array}$ & 13.2 & 17 & 12 & 1.4 \\
\hline $\begin{array}{l}\text { Poly(ethylene- } \\
\text { vinylalcohol) }\end{array}$ & 0.98 & 2 & 2 & 1 \\
\hline $\begin{array}{l}\text { TPX }{ }^{\oplus} \text { MX002 } \\
\text { (poly methyl 1- } \\
\text { pentene) }\end{array}$ & 4.8 & 3 & 8 & 0.4 \\
\hline $\begin{array}{l}\text { AFLAS } \\
\text { (fluorinated } \\
\text { elastomer) }\end{array}$ & 24.4 & 1 & 130 & 0.008 \\
\hline
\end{tabular}

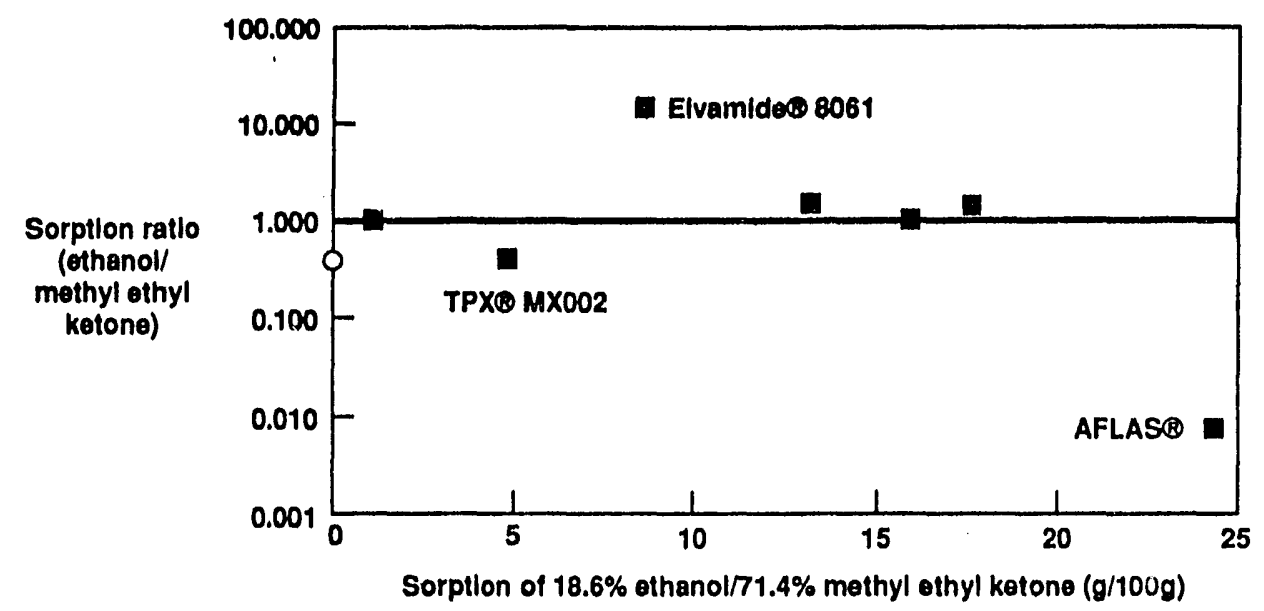

221-GAP

Figure 10. Sorption of ethanol and methyl ethyl ketone by polymers. 
Polymers that have a moderate to high preferential sorption for one of the mixture components are good candidates for pervaporation membranes. These materials would have moderate to high sorption ratios and low to moderate mixture sorption, as defined by our test procedure. In Figure 10 we see that Elvamide 8061 (Dupont De Nemours and Co.), an amorphous polyamide, is the most suitable material for the ethanol/methyl ethyl ketone separation, with a sorption ratio of 15 and a mixture sorption of 8.6 wt\%. Materials with low sorption ratios and low mixture sorption, such as TPX ${ }^{\oplus}$ MX002 (Mitsui Petrochemical Industries, Inc.). polymethylpentene, are relatively impermeable and hence less suitable for pervaporation membranes. Subsequent pervaporation experiments confirmed these conclusions and the value of our screening test. We found that Elvamide-based membranes had an ethanol/methyl ethyl ketone permeation selectivity of 9 to 12 for the ethanol/methyl ethyl ketone mixture at $25^{\circ} \mathrm{C}$. The TPXbased membranes had considerably lower fluxes and an ethanol/methyl ethyl ketone selectivity less than 1 .

If the polymer preferentially sorbs methyl ethyl ketone over ethanol then, based on our definition, the sorption ratio is less than 1 . This is the case for the fluorinated elastomer AFLAS ${ }^{\odot}$ ( $3 \mathrm{M}$ Industrial Chemical Products), which has a sorption ratio of 0.008 , i.e. a methyl ethyl ketone / ethanol sorption ratio of 130 . We did not consider this polymer to be a good membrane candidate because it had very high sorption of the mixture $(24.4 \mathrm{wt} \%)$. Polymers that have very high sorption are swollen by the feed stream and, despite the high pure component sorption ratio, the membrane has very poor pervaporation selectivity.

Our approach uses a sorption ratio based on the sorption of pure species in separate experiments. We expect that when the species are present in a mixture, the relative sorption of each species will differ from the pure component sorption ratio. This difference in sorption behavior is due to non-ideal behavior of mixed organic liquids as well as the effect of a species with high sorption swelling the polymer and dragging in a second species with a lower sorption coefficient. However, these deviations from ideal behavior are significant only when one of the species has very high sorption in the polymer, relative to the other, as in the case of the high sorption of methyl ethyl ketone in AFLAS ${ }^{\odot}$. For cases of moderate to low sorption, the pure component sorption ratio provides a good first estimate of the pervaporation selectivity of the membrane.

We used the same approach to select membrane polymers for the toluene/methyl cyclohexane mixture. The sorption data are given in Table 6 and Figure 11. All of the poiymers had a sorption ratio greater than 1, indicating preferential sorption of toluene. Glassy polymers such as cellulose acetate and polyamide (Elvamide) had low sorption ratios and low mixture sorption. The best results were obtained with more flexible polymers such as polyurethanes, Pellethane ${ }^{\oplus}$ (Dow Chemical Co.), Estane ${ }^{\oplus}$ (B.F. Goodrich Chemical Group), and polyamide-polyether block copolymers, Pebax ${ }^{\oplus}$ (Atochem Inc.) and Vestamid ${ }^{\bullet}$ (Nuodex Inc.). 
Table 6. Sorption of Toluene and Methyl Cyclohexane in Polymers

\begin{tabular}{|c|c|c|c|c|}
\hline \multirow{2}{*}{ Polymer } & \multicolumn{3}{|c|}{ Sorption (g liquid/100 g polymer) } & \multirow{2}{*}{$\begin{array}{c}\text { Sorption } \\
\text { ratio } \\
\text { (toluene/MCH) }\end{array}$} \\
\hline & $50 \%$ toluene & $\begin{array}{l}\text { Pure } \\
\text { toluene }\end{array}$ & $\begin{array}{l}\text { Purs } \\
\mathrm{MCH}\end{array}$ & \\
\hline Cellose acetate & 6 & 8 & 7 & 1.1 \\
\hline Elvamide $^{\oplus} 8061$ & 3 & 6 & 5 & 1.2 \\
\hline $\begin{array}{l}\text { Vestamid } \\
\text { E-55-M53 }\end{array}$ & 19 & 22 & 9 & 2.4 \\
\hline $\begin{array}{l}\text { Vestamid } \\
\text { E-62-M53 }\end{array}$ & 17 & 19 & 5 & 3.8 \\
\hline $\begin{array}{l}\text { Pebax } 5562 \\
\text { (polyamide- } \\
\text { polyether block } \\
\text { copolymer }\end{array}$ & 22 & 31 & 11 & 2.8 \\
\hline Pebax 6333 & 14 & 17 & 4 & 4.3 \\
\hline $\begin{array}{l}\text { Estane } 5713 \\
\text { (polyurethane) }\end{array}$ & 18 & 133 & 2 & 67 \\
\hline Estane 58133 & 13 & 29 & 2 & 15 \\
\hline $\begin{array}{l}\text { Pellethane }^{\oplus} \\
\text { (polyurethane) } \\
\text { 2102-55D }\end{array}$ & 12 & 25 & 2 & 13 \\
\hline $\begin{array}{l}\text { Pellethane } 2103- \\
\text { 55D }\end{array}$ & 19 & 32 & 5 & 6.4 \\
\hline $\begin{array}{l}\text { Pellethane }{ }^{\oplus} 2355- \\
\text { 55D }\end{array}$ & 10 & 20 & 1 & 20 \\
\hline $\begin{array}{l}\text { Crosslinked } \\
\text { polybutadiene }\end{array}$ & 544 & 636 & 451 & 1.4 \\
\hline
\end{tabular}




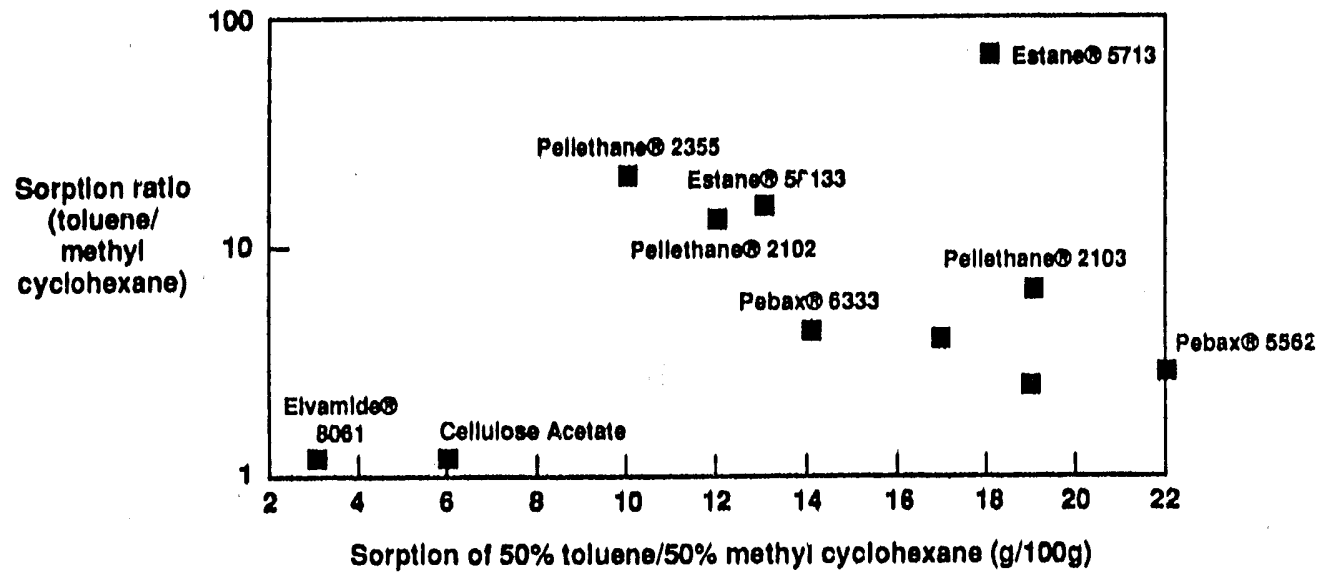

228.GHP

Figure 11. Sorption ratio as a function of mixture sorption for toluene and methyl cyclohexane.

The sorption ratio and mixture sorption are strongly linked to the polymer structure, as illustrated by the Pellethane family of polyurethanes. Pellethane 2102 and 2355 are polyester-based polyurethanes and Pellethane 2103 is a polyether polyurethane. The flexible polyether linkages in Pellethane 2103 enable the polymer to sorb hydrocarbons readily. Consequently the polymer is not very selective in its sorption of methyl cyclohexane or toluene but has a high sorption of both. The polyester polyurethanes, Pellethane 2102 (polycaprolactone ester) and Pellethane 2355 (polyadipate ester) have a more rigid polymer structure which contributes to the lower mixture sorption and the higher toluene/methyl cyclohexane sorption ratio compared with the polyether polyurethane.

We did not conduct an extensive search for materials for the ethyl acetate/water separation. Polyamides are hydrophilic polymers and we used the Elvamide membranes developed for the ethanol/methyl ethyl ketone separation for the dehydration of ethyl acetate. The validity of this choice was confirmed by the high separation factors that were measured in subsequent pervaporation experiments.

\subsection{Module Development}

Membranes were incorporated into modules that maximized the available membrane area in a compact volume. The spiral-wound configuration shown in Figure 7 was used because of its high packing density and ease of fabrication.

Spiral-wound modules are conslructed by the procedure shown schematically in Figure 12 . The membrane is first cut to size and folded around the feed spacer material, usually a polypropylene mesh, and the product collection pipe. The membrane envelope is then moved to the wind-up machine. The product collection pipe is placed in the jaws of a motor or hand-driven clutch, and the permeate spacer material is glued to the pipe. During the winding operation, the material is kept under slight tension and the membrane envelope is glued along the sides and ends. When completely wound up, a layer of fabricreinforced tape is used to seal the module. After the glue has fully cured, the module is wrapped with fiberglass and endcaps are added to provide a feed inlet and per meate and residue outlets. 


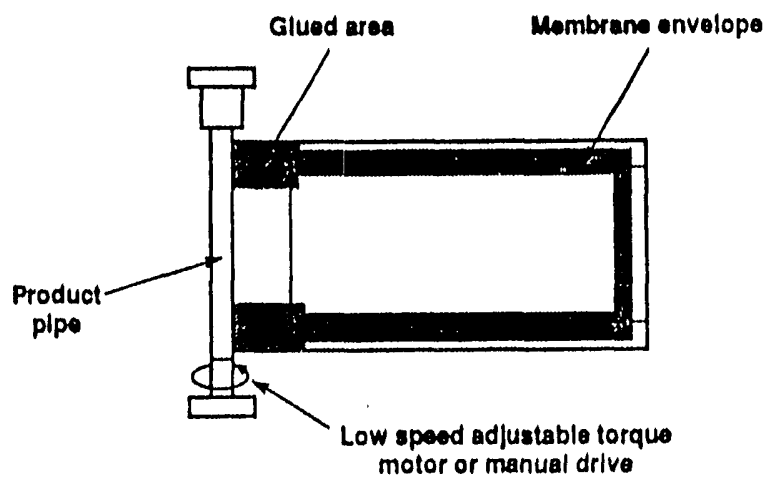

Do7.F

Figure 12. Schematic of the MTR module-winding procedure.

We used two module sizes in this study. Bench-scale modules used to separate toluene from methyl cyclohexane were $36 \mathrm{~cm}$ long and $6.4 \mathrm{~cm}$ in diameter and contained $0.2 \mathrm{~m}^{2}$ area. The module used in the ethanol/ methyl ethyl ketone separation was a pilot-scale module, $85 \mathrm{~cm}$ long and $5.7 \mathrm{~cm}$ in diameter, and contained $0.5-1.0 \mathrm{~m}^{2}$ effective membrane area.

One of the principal objectives of this program was to develop a solvent-resistant membrane module. In an industrial plant a pervaporation module will be exposed to hot solvent mixtures for extended periods of time, therefore the module must be able to withstand attack by the feed mixture. Table 7 lists the module components along with their function and the construction material selected for this study.

Table 7. Module Components, Functions and Construction Materials

\begin{tabular}{|l|l|l||}
\hline \multicolumn{1}{|c|}{ Component } & \multicolumn{1}{|c|}{ Function } & \multicolumn{1}{|c|}{$\begin{array}{c}\text { Material used for } \\
\text { organic feed streams }\end{array}$} \\
\hline Sealing glue & $\begin{array}{l}\text { Separates feed and permeate } \\
\text { compartments; seals } \\
\text { membrane envelopes }\end{array}$ & $\begin{array}{l}\text { Amine-cured epoxy } \\
\text { resins }\end{array}$ \\
\hline Endcaps & $\begin{array}{l}\text { Anti-telescoping devices; } \\
\text { prevent module unwinding }\end{array}$ & Stainless steel \\
\hline $\begin{array}{l}\text { O-ring/U-cup } \\
\text { seals }\end{array}$ & $\begin{array}{l}\text { Ensure proper feed flow; } \\
\text { prevent feed bypass }\end{array}$ & PTFE \\
\hline $\begin{array}{l}\text { Spacers } \\
\text { Keep the feed and permeate } \\
\text { flow channel open }\end{array}$ & Polypropylene mesh \\
\hline Overwrap & Mechanical support & Glass fiber/epuxy \\
\hline Product pipe & Collects permeate & Stainless steel \\
\hline $\begin{array}{l}\text { Module } \\
\text { housing }\end{array}$ & Containment vessel & Stainless steel \\
\hline
\end{tabular}

A key component of the module is the glue used to seal the mumbrane envelope. Pinholes or softening of the glue provide flow channels resulting in leaks from the feed to the permeate streams and dramatically reduce membrane selectivity. A number of glues were screened using a procedure identical to the one used to select the support membrane. Membrane swatches were glued together and immersed 
in the hot feer mixture for 120 hours. The bond was studied to determine the residual peel strength and the resistance to swelling and cracking. Amine-cured epoxy resins were found to be the most chemicallyresistant glues.

Module spacers are typically a polypronylene mesh that is placed inside and between adjacent membrane envelopes. The spaces provide flow channels for the feed and permeate streams, prevent the membrane envelopes from collapsing under pressure and increase the mass transfer coefficient by acting as a static mixer in the flow channel. Polypropylene was used in the modules becalluse it was not altacked by the mixtures separated in this program. If more aggressive mixtures are to be separated, stainless steel spacers could be used.

The end-capss are anti-telescoping devices mounted on either side of the spiral-wound module. They prevent the module from unraveling and also regulate the feed flow pattern in the module housing. We used PVC end-caps for the modules used to separate the toluene/methyl cyclohexane mixture. Since PVC is not resistant to methyl ethyl ketone, we used stainless steel end-capss for the ethanol/methyl ethyl ketone separation. Elastomeric seals are attached to the end caps and prevent the feed stream from flowing around the module instead of through the feed channels. Viton seals were used for the toluene/methyl cyclohexane separation and were replaced with Teflon seals in the ethanol/methyl ethyl ketone separation modules.

The module overwrap provides mechanical strength to the module and functions as a protective cover when the module is out of the housing. We used al glass fiber/epoxy combination that is used as an overwrap on our regular modules. The glass fiber was inert to the feed mixtures but the epoxy binder showed some degradation when exposed to the ethanol/methyl ethyl ketone mixture. This problem was observed at the very end of the program and we were unable to resolve it sucessifully. Replacing the regular epoxy hinder with a more chemical-resistant epoxy would be the first step in stabilizing the overcerat.

The module and housing design described in the preceding paragraphs performed very well. We did not conduct any long.term tests on the modiules but examination of the modules after pervaporation tests revealed ne significant degradation. Modules did show a drop in selectivity as compared to tests with individual membrante stamps (10) $\mathrm{cm}^{2}$ area). This decrease may be due to weakly glued seams o: failure of the glue. However the membrane flux did not increase dramatically as would be expected in the case of catastrophic failure of the glued seams. We conclude that the glue line defects are few and small. Since the pump we used was under-rated for the module design, another possible explanation is that, at low flow rates, the liquid phase mass transfer resistance becomes the rate-limiting factor in the pervaporation process.

\subsection{Pervalperation Test System}

We constructed a pervaporation iest unit for testing the membranes and modules produced in this program. A photograph and schematic diagram of the system are shown in Figure 13. The system was specially designed for aggressive organic mixlures and was constructed primarily from stainless steel with some glass fittings. The system can be operated with $2.10 \mathrm{l}$. of solution and was completely instrumented to allow monitoring of the operating conditions. Tests can be made of both individual pieces of membrane and membrane modules. Initial screening tests were performed using $100 \mathrm{~cm}^{2}$ disks of membrane in a titanium test cell. The best membranes were scaled up to modules containing $0.2-1.0 \mathrm{~m}^{2}$ membrane area for evaluation. 
During a test, the organic-organic mixture feed solution was pumped through the membrane test cell or module by a small centrifugal pump. As the feed circulated across the membrane surface, a small fraction passed through the membrane as permeate vapor. This permeate was collected in a cold trap chilled with liquid nitrogen. The system was equipped with two permeate traps. The permeate stream was switched periodically from trap to trap, allowing the permeate to be collected continuously. The feed solution temperature, permeate pressure and feed flow rate were all adjustable. Thus, our experiments with the laboratory system could be set up to simulate a range of pervaporation conditions.

Samples of the feed and permeate liquids were analyzed in a gas chromatograph to determine composition. The overall permeation rate was determined from the rates of accumulation of material in the cold traps. These experimental data were used to calculate the permeation rates of the mixture components and the membrane selectivity.
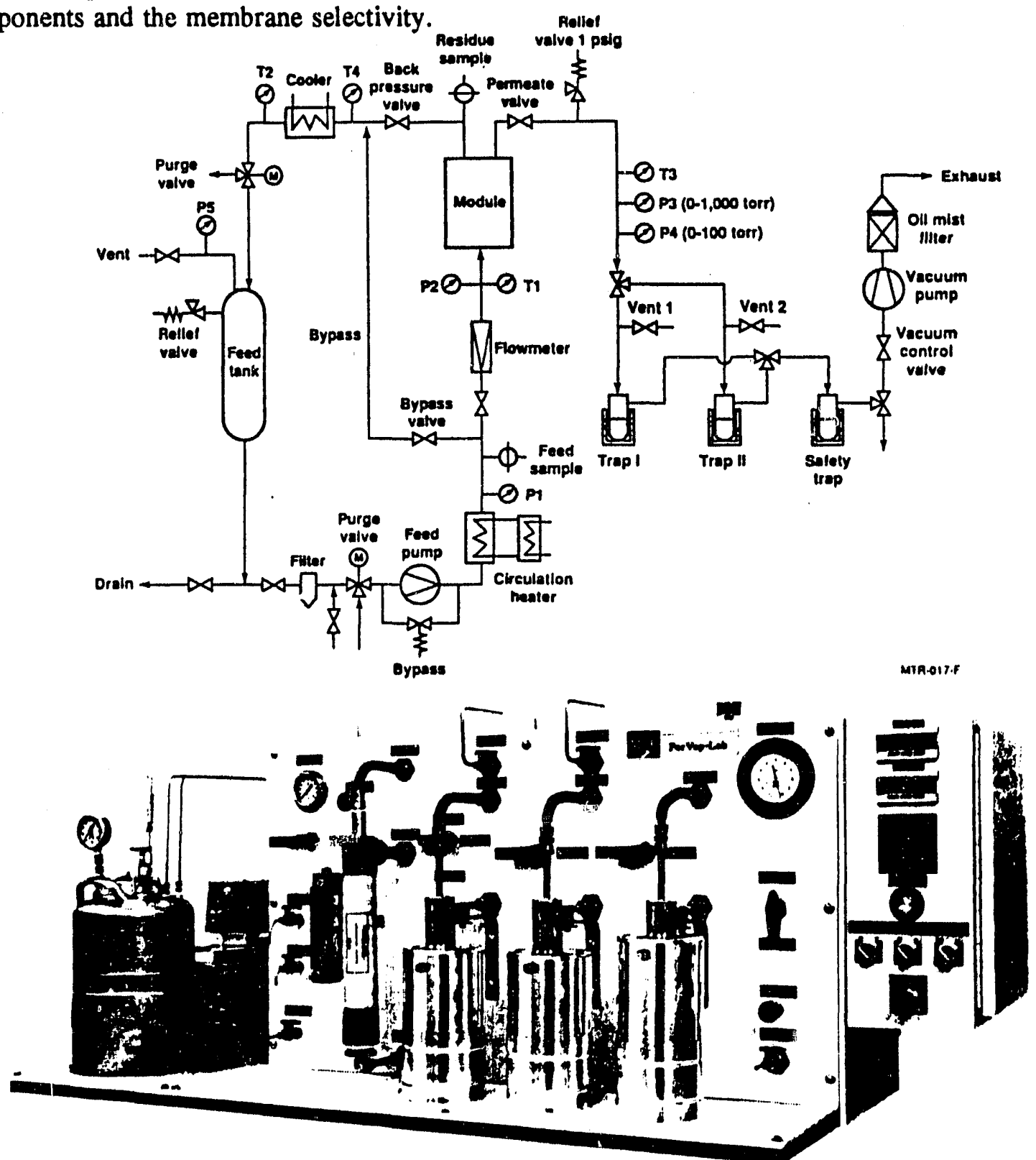

Figure 13. Flow diagram and photograph of MTR, Inc. laboratory-scale pervaporation test loop. 


\subsection{Pervaporation Results}

We separated three organic mixtures, ethanol/methyl ethyl ketone, toluene/methyl cyclohexane and ethyl acetate/water, using pervaporation. The mixture compositions and temperatures are listed in Table 8. We were able to obtain a good separation for all three mixtures, demonstrating that pervaporation can be used to separate organic azeotropic mixtures, an operation that is not feasible using simple distillation. The pervaporation results for each of the mixtures is discussed in the following sections.

Table 8. Feed Mixtures for Pervaporation

\begin{tabular}{|c|c|c|c|c|}
\hline \multicolumn{2}{|c|}{ Components } & \multirow{2}{*}{$\begin{array}{l}\text { Concentration } \\
\text { of } \mathrm{A}(\mathrm{wt} \%)\end{array}$} & \multirow{2}{*}{$\begin{array}{l}\text { Feed } \\
\text { temperature } \\
(\bullet \mathrm{C})\end{array}$} & \multirow{2}{*}{ Comments } \\
\hline A & B & & & \\
\hline Ethanol & $\begin{array}{l}\text { Methyl ethyl } \\
\text { ketone }\end{array}$ & $8-35$ & $25-55$ & $\begin{array}{l}\text { Homogeneous, minimum- } \\
\text { boiling azeotrope }\end{array}$ \\
\hline Toluene & $\begin{array}{l}\text { Methyl } \\
\text { cyclohexane }\end{array}$ & $42-63$ & $30-60$ & Close-boiling mixture \\
\hline Ethyl acetate & Water & $97-99$ & $40-70$ & $\begin{array}{l}\text { Heterogeneous minimum- } \\
\text { boiling azeotrope }\end{array}$ \\
\hline
\end{tabular}

\subsubsection{Ethanol/Methyl ethyl ketone}

Sorption tests showed that polyamide (Elvamide) membranes were the most suitable for the separation of ethanol/methyl ethyl ketone mixtures by pervaporation. Table 9 presents characteristic performance data for polyamide films, thin-film composite membranes and spiral-wound modules. The table lists the overall separation factor, $\beta_{\text {pernap }}$ and also the calculated membrane selectivity, $\alpha_{\text {membraso }}$. The overall separation factor is the combination of the separation achieved in the evaporation and membrane permeation steps. Since the feed composition is near-azeotropic, there is no separation due to evaporation and the separation is due to the membrane alone. The membrane selectivity is the ratio of the permeability coefficient of ethanol and methyl ethyl ketone. The overall separation factor and membrane selectivity differ because the former refers to the separation of the mixture components while the latter describes their relative permeation rates through the membrane. 
Table 9. Pervaporation Results for the Ethanol/Methyl Ethyl Ketone Mixture

\begin{tabular}{|c|c|c|c|c|c|c|}
\hline $\begin{array}{l}\text { Feed } \\
\text { temp. } \\
\left({ }^{\circ} \mathrm{C}\right)\end{array}$ & $\begin{array}{c}\text { Permeate } \\
\text { pressure } \\
\text { (torr) }\end{array}$ & $\begin{array}{c}\text { Feed } \\
\text { conc. } \\
\text { (wt \% ethanol) }\end{array}$ & $\begin{array}{c}\text { Permeate } \\
\text { conc. } \\
\text { (wt\% ethanol) }\end{array}$ & $\begin{array}{c}\text { Membrane } \\
\text { flux } \\
\left(\mathrm{kg} / \mathrm{m}^{2} \mathrm{~h}\right) \\
\end{array}$ & $\begin{array}{c}\beta_{\text {pervap }} \\
\text { (EtOH/MEK) }\end{array}$ & $\begin{array}{c}\alpha_{\text {mombras }} \\
(\mathrm{EtOH} / \mathrm{MEK})\end{array}$ \\
\hline \multicolumn{7}{|c|}{ 1. $24 \mu \mathrm{m}$ Elvamide ${ }^{\oplus i l m}$ stamps } \\
\hline $\begin{array}{l}25 \\
55\end{array}$ & $\begin{array}{l}10 \\
10\end{array}$ & $\begin{array}{l}8-28 \\
8-28\end{array}$ & $\begin{array}{l}40-68 \\
35-59\end{array}$ & $\begin{array}{l}0.06-0.08 \\
0.18-0.68\end{array}$ & $\begin{array}{l}4-9 \\
4-6\end{array}$ & $\begin{array}{r}9-12 \\
-4\end{array}$ \\
\hline \multicolumn{7}{|c|}{ 2. Polyetherimide/PDMS/Elvamide ${ }^{\oplus}$ stamps } \\
\hline $\begin{array}{l}25 \\
55 \\
\end{array}$ & $\begin{array}{l}10 \\
10 \\
\end{array}$ & $\begin{array}{c}18 \\
17.5\end{array}$ & $\begin{array}{l}61 \\
49 \\
\end{array}$ & $\begin{array}{c}0.08 \\
0.7\end{array}$ & $\begin{array}{c}7 \\
4.5 \\
\end{array}$ & $\begin{array}{l}9.5 \\
3.8 \\
\end{array}$ \\
\hline \multicolumn{7}{|c|}{ 3. Polyetherimide/crosslinked Elvamide ${ }^{\oplus}$ membrane modules } \\
\hline $\begin{array}{l}25 \\
55\end{array}$ & $\begin{array}{c}3.0 \\
17\end{array}$ & $\begin{array}{l}14 \\
32\end{array}$ & $\begin{array}{l}21 \\
41\end{array}$ & $\begin{array}{l}0.25 \\
1.04\end{array}$ & $\begin{array}{l}1.6 \\
1.5\end{array}$ & $\begin{array}{l}1.5 \\
1.8 \\
\end{array}$ \\
\hline
\end{tabular}

Data obtained with polyamide films are presented in Figures 14 and 15 along with the vaporliquid equilibria. These data represent experiments at two feed temperatures, $25^{\circ} \mathrm{C}$ and $55^{\circ} \mathrm{C}$. The data show that pervaporation produces a permeate stream that is enriched in ethanol, in excess of that expected for evaporation alone. The membrane system breaks the azeotrope, producing an ethanol-enriched permeate and a methyl ethyl ketone-enriched residue stream.

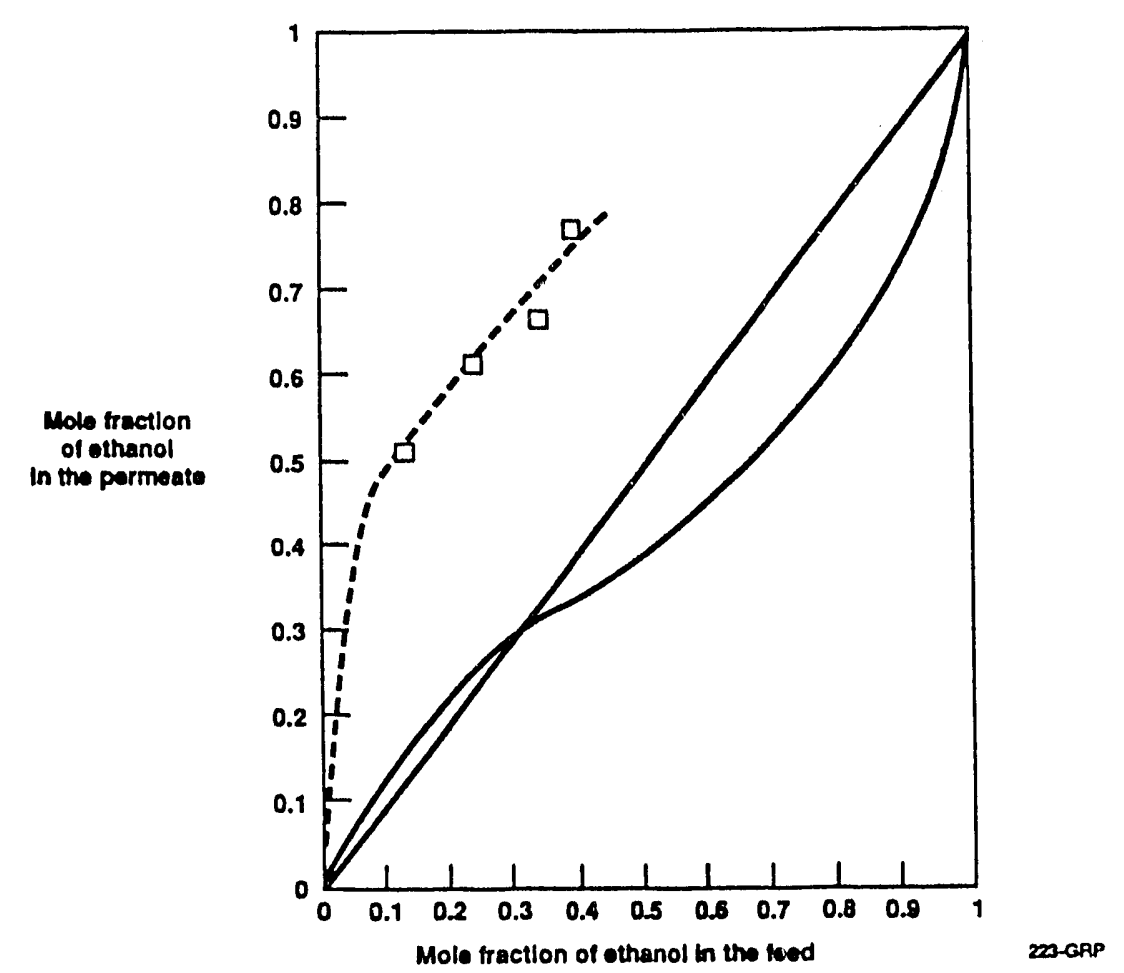

Figure 14. Pervaporation of ethanol/methyl ethyl ketone mixtures through polyamide films at $25^{\circ} \mathrm{C}$. 


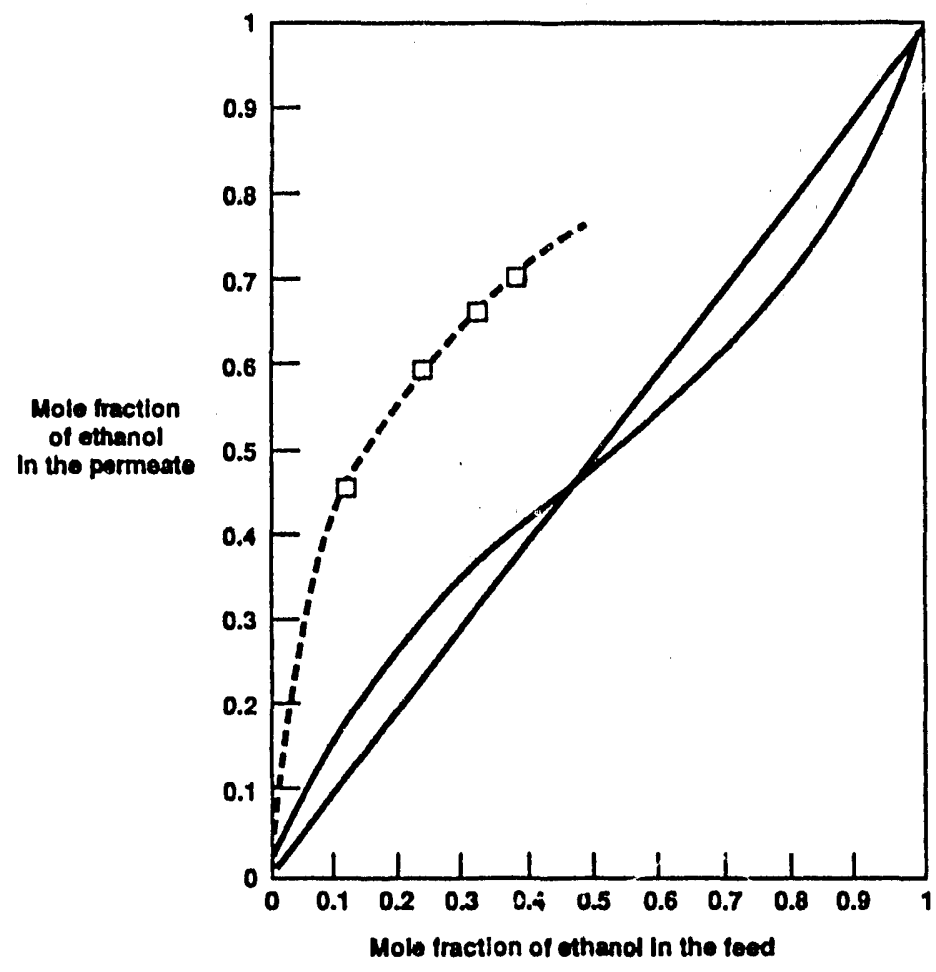

2OGRP

Figure 15. Pervaporation of ethanol/methyl ethyl ketone mixtures through polyamide films at $55^{\circ} \mathrm{C}$.

The data obtained for permeation through polyamide films show that modest fluxes can be obtained with relatively thick films $(24 \mu \mathrm{m})$. This indicates that the film is highly swollen with sorbed ethanol and methyl ethyl ketone. Our initial attempts to make high-flux, thin-film composite membranes with polyamide were unsuccessful because the selective layer was destroyed by excessive swelling. The layer was pushed into the pores of the support leading to loss of flux and selectivity.

We resolved the swelling-induced flux and selectivity loss by coating an intermediate layer of polydimethylsiloxane between the permselective polyamide layer and the support membrane. Polydimethylsiloxane seals the pores in the support, providing a smooth substrate for the polyamide layer. Consequently, when the permselective layer swells, it is unable to creep into the pores of the support. Therefore, there is no damage to the support by the feed solution. The data in Table 9 show that thinfilm composite polyamide membranes on a polyetherimide/polydimethylsiloxane support had the same selectivity as thick dense films of Elvamide. Because of the thinner permselective layer, the flux obtained with the composite membrane is higher than for the film.

The change to the crosslinked polyamide membrane used in the modules was made because of difficulty in scaling-up the production of membranes with a polydimethylsiloxane intermediate layer. A melamine formaldehyde resin was mixed into the coating solution and the polyamide-coated polyetherimide membranes were heat treated to complete the crosslinking process. In initial tests these membranes showed lower swelling than non-crosslinked polyamide membranes when exposed to ethanol. Membrane selectivity was unchanged by the crosslinking process. However, modules made from this membrane had significantly lower selectivity than the membrane stamps, as seen in Table 9. Possible explanations for the poor selectivity characteristics of the modules include non-uniform crosslinking, resulting in regions of highly swollen, damaged membrane, or failure of the modules due to permeation through the glue lines. 


\subsubsection{Toluene/Methyl cyclohexane}

The toluene/methyl cyclohexane mixture is a close-boiling mixture that does not form an azeotrope. Methyl cyclohexane boils at $101^{\circ} \mathrm{C}$ and toluene at $110^{\circ} \mathrm{C}$. This mixture was selected as a model because it is characteristic of other aromatic/cyclo-aliphatic mixtures that do form azeotropes.

Tests showed that the best membrane material for this separation was Pebax 4011 , a polyamidepolyether block copolymer, supported on a polyetherimide membrane. Characteristic pervaporation data is presented in Table 10. The data indicate that the membrane is about times more permeable to toluene than to methyl cyclohexane. Increasing the pervaporation temperature results in higher membrane flux because of the increase in the vapor pressure driving force for permeation. Another factor is increased permeability of the membrane due to greater swelling of the polymer at higher temperatures. The membrane selectivity, however, decreases at the higher temperature due to swelling of the membrane.

Table 10. Pervaporation Results for the Toluene/Methyl Cyclohexane Mixture

\begin{tabular}{|c|c|c|c|c|c|c|}
\hline $\begin{array}{c}\text { Feed } \\
\text { temp. } \\
\left({ }^{\circ} \mathrm{C}\right)\end{array}$ & $\begin{array}{c}\text { Permeate } \\
\text { pressure } \\
\text { (torr) }\end{array}$ & $\begin{array}{l}\text { Feed } \\
(w+\% \text { toluene })\end{array}$ & $\begin{array}{l}\text { Permeate } \\
\text { (wt\% toluene) }\end{array}$ & $\begin{array}{l}\text { Membrane } \\
\text { (kg/mitis) }\end{array}$ & $\begin{array}{c}\beta_{\text {pornep }} \\
(\mathrm{Tol} / \mathrm{MCH})\end{array}$ & $\begin{array}{l}\alpha_{\text {membron }} \\
(\text { Tol. } / \mathrm{MeCH})\end{array}$ \\
\hline \multicolumn{7}{|c|}{ 1. Polyetherimide/Pebax ${ }^{\oplus} 4011 /$ cellulose acetate stamps } \\
\hline $\begin{array}{l}30 \\
60\end{array}$ & $\begin{array}{l}6 \\
5\end{array}$ & $\begin{array}{l}43 \\
44\end{array}$ & $\begin{array}{l}85 \\
82\end{array}$ & $\begin{array}{l}0.3 \\
1.3\end{array}$ & $\begin{array}{l}7.4 \\
5.9\end{array}$ & $\begin{array}{c}14 \\
9\end{array}$ \\
\hline \multicolumn{7}{|c|}{ 2. Polyetherimide/Pebax ${ }^{\oplus 011 / \text { cellulose acetate membrane modules }}$} \\
\hline 30 & 10 & 58 & 83 & 0.2 & 3.5 & 9 \\
\hline
\end{tabular}

The pervaporation performance data are presented graphically in Figure 16 along with the vapor liquid equilibria for the toluene/methyl cyclohexane mixture. The membranes favor toluene, the less volatile component, which results in evaporation and permeation selectivities that partially offset each other. Consequently the overall separation factor is always less than the membrane selectivity. The permeate composition lies below the vapor-liquid equilibrium line and even below the " $y=x$ " line. 


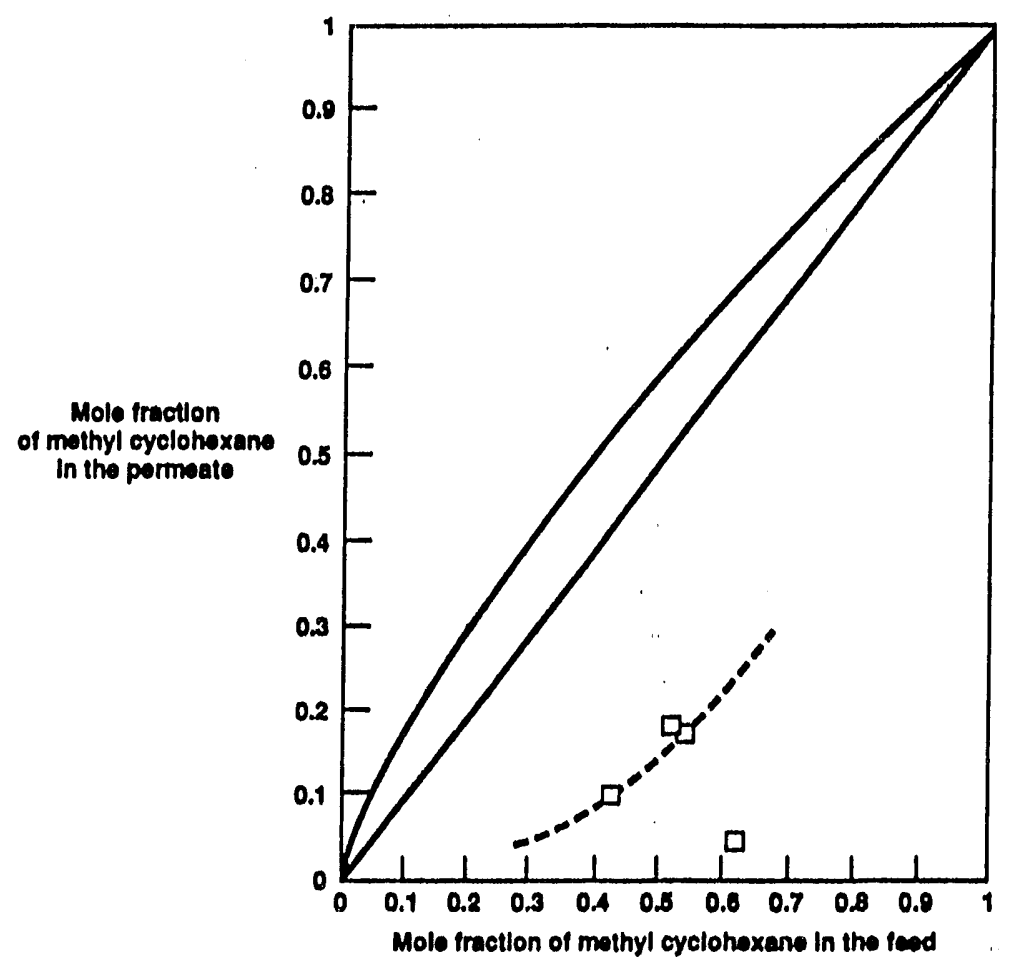

222-GAP

Figure 16. Permeation of toluene/methyl cyclohexane mixtures through polyetherimide/Pebax $4011 /$ cellulose acetate composite membranes at $60^{\circ} \mathrm{C}$.

The results suggest that this membrane is best suited to treating methyl cyclohexane streams in a polishing step to remove small quantities of toluene present. The process would save the energy required to volatilize the methyl cyclohexane in a conventional distillation separation. Furthermore, since the membrane will encounter low concentrations of toluene, the permeation selectivity will not be compromised by membrane swelling.

The pervaporation performance of the Pebax membrane module is slightly poorer than that obtained with membrane stamps. We believe this is because the module was operated at higher concentrations of toluene in the feed than in the stamp experiments. Toluene is the preferentially permeating component; at higher concentrations it will have a greater effect on membrane swelling and selectivity loss. Swelling of the glue in the module and permeation through the glue lines is another possible cause for the drop in performance.

All the Pebax composite membranes were coated with a thin layer of cellulose acetate on top of the Pebax layer. It is likely that the cellulose acetate layer acts together with the Pebax as a permselective barrier, preventing direct contact with the feed liquid, and minimizing swelling. We were unable to determine the permselectivity of cellulose acetate in permeation tests because no flux could be measured. Based on the resistance model, we would expect the selectivity of this bilayer membrane to be between the intrinsic values for Pebax and cellulose acetate. This conclusion is supported by the higher selectivity observed with the composite membrant than with thick films of Pebax. The role of the cellulose acetate layer remains to be explored further. 


\subsubsection{Ethyl acetate/water}

Ethyl acetate and water form a heterogenous minimum boiling azeotrope containing 94 wt\% water at $70^{\circ} \mathrm{C}$. This is representative of a number of moderately hydrophilic, polar organic solvents including the higher ketones (methyl ethyl ketone), alcohols (n-butanol and s-butanol) and esters (butyl acetate). Because the liquid phase separates into organic-rich and water-rich phases, separation can be accomplished using a single distillation column and a phase separator. Our goal was to find a selective membrane that could replace the distillation operation with pervaporation.

The ideal pervaporation membrane for dehydrating moderately hydrophilic, polar organic streams is a hydrophilic polymer that is insoluble in moderately polar or nonpolar solvents. The polyamide, Elvamice, membranes developed for the separation of ethanol from methyl ethyl ketone were found to be good candidates for this application. Results from the pervaporation tests are presented in Table 11 and Figure 17. All the data were obtained with Elvamide film stamps. We did not complete the scale-up of these membranes to modules because of the problems with the module fabrication glue stability observed in the modules for ethanol/methyl ethyl ketone separation.

Table 11. Pervaporation Results for the Ethyl Acetate/Water Mixture Separation Using Polyetherimide/Crosslinked Elvamide ${ }^{\star}$ Composite Membranes (permeate pressure: 10 torr)

\begin{tabular}{|c|c|c|c|c|c|}
\hline $\begin{array}{l}\text { Feed } \\
\text { temp. } \\
\left({ }^{\circ} \mathrm{C}\right)\end{array}$ & $\begin{array}{l}\text { Feed } \\
\text { (\% ethyl } \\
\text { acetate) }\end{array}$ & $\begin{array}{l}\text { Permeate } \\
\text { (\% ethyl } \\
\text { acetate })\end{array}$ & $\begin{array}{l}\text { Membrane } \\
\left(\mathrm{kg} / \mathrm{m}^{2} \mathrm{t}\right)\end{array}$ & $\begin{array}{c}\beta_{\text {porvep }} \\
\left(\mathrm{H}_{2} \mathrm{O} / \mathrm{EtAC}\right)\end{array}$ & $\begin{array}{c}\alpha_{\text {mombrans }} \\
\left(H_{2} \mathrm{O} / \mathrm{EtAc}\right)\end{array}$ \\
\hline 40 & 98.2 & 4.3 & 0.19 & 1,250 & 730 \\
\hline 55 & 98.3 & 8.6 & 0.35 & 620 & 300 \\
\hline 60 & 98.4 & 7.0 & 0.39 & 880 & 390 \\
\hline 70 & 98.7 & 7.4 & 0.36 & 960 & 410 \\
\hline
\end{tabular}




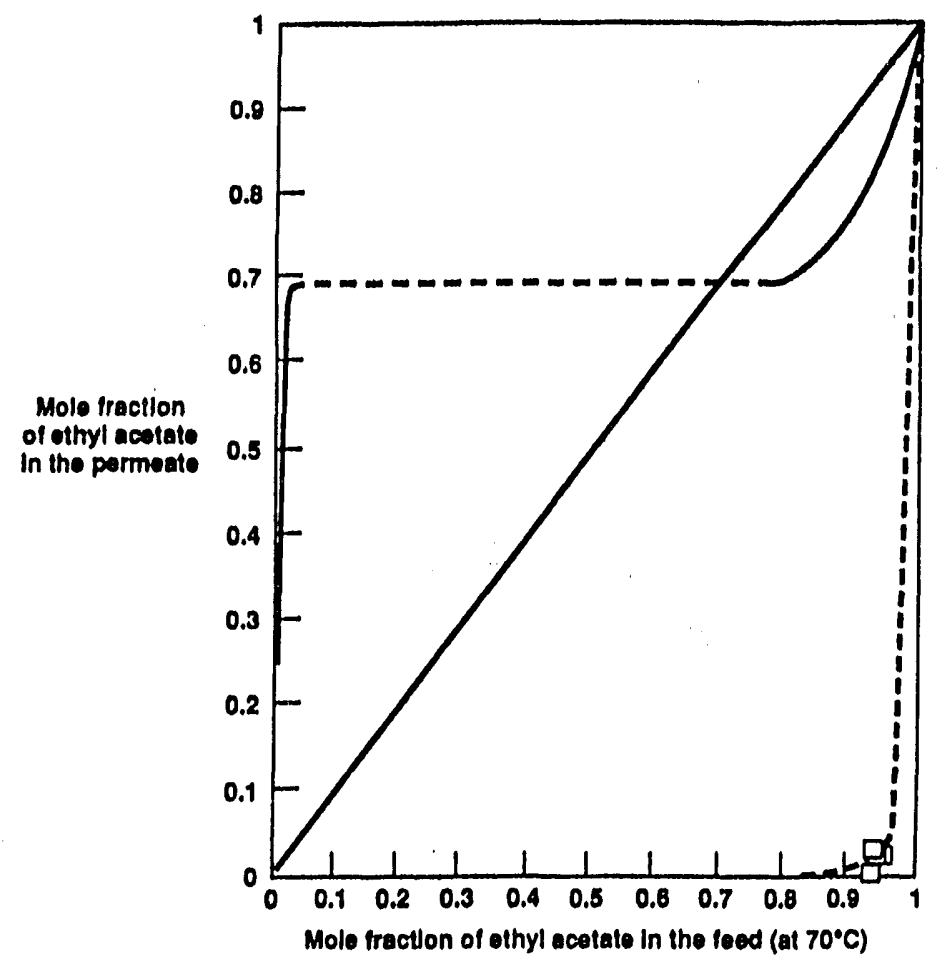

225.GAP

Figure 17. Permeation of ethyl acetate-water mixtures through polyamide films at $70^{\circ} \mathrm{C}$.

The data indicate that the membrane is highly water-selective, separating the feed stream into a water-rich permeate and organic-rich residue stream. Water in the feed (1-2\%) is concentrated to 90-95\% in the permeate, a 50- to 100-fold enrichment. Separation factors as high as 1,000 for water/ethyl acetate were measured and the membrane selectivity was greater than 300 . The permeate stream phase separated into a large water-rich phase and a small organic-rich phase. In a pilot-scale separation, the organic component would be recycled to the feed stream. With further improvements in membrane selectivity a single-phase, water-rich permeate, suitable for discharge into the process sewer, could be obtained.

We examined the feasibility of using the polyamide composite membrane for dehydrating other organic streams, including methyl ethyl ketone, acetone and methylene chloride. The membrane water/organic selectivity was high $(\sim 100)$ for acetone but lower for methyl ethyl ketone and methylene chloride $(\sim 10)$.

\subsection{Study of Pervaporation Operating Parameters}

The pervaporation operating parameters, including the permeate pressure, feed composition and feed temperature have a significant effect on the performance of all the systems. The influence of the individual operating parameters on the membrane flux and separation factor are discussed in the following sections. 


\subsubsection{Permeate Pressure}

The driving force for permeation in the pervaporation process is the difference between the vapor pressure of the permeant in the feed liquid, and its vapor pressure in the permeate stream. At a constant feed composition and temperature, the vapor pressure of the feed liquid will remain constant and the driving force for permeation will vary directly with the permeate pressure. The data from the pervaporation of ethanol/methyl ethyl ketone mixtures presented in Table 12 support this conclusion. The total permeate flux doubles, from 0.067 to $0.13 \mathrm{~kg} / \mathrm{m}^{2} . \mathrm{h}$, as the permeate pressure is dropped from 50 to 10 torr. The vapor pressure of the feed liquid is 96 torr, which corresponds to a pressure difference almost doubled from 46 to 86 torr. The total flux also doubles to match the change in driving force.

Table 12. The Effect of Permeate Pressure on the Pervaporation Separation Factor Membrane: Elvamide ${ }^{\oplus}$ Film

Feed: $18.2 \%$ Ethanol, $81.8 \%$ Methyl Ethyl Ketone at $25^{\circ} \mathrm{C}$

\begin{tabular}{|c|c|c|}
\hline $\begin{array}{c}\text { Permeate pressure } \\
\text { (torr) }\end{array}$ & $\begin{array}{c}\text { Membrane flux } \\
\mathrm{kg} / \mathrm{m}^{2} \cdot \mathrm{h}\end{array}$ & $\begin{array}{c}\beta_{\text {pormp }} \\
\text { (EtOH/MEK) }\end{array}$ \\
\hline 50 & $0.01 ; 7$ & 3.5 \\
\hline 10 & 0.13 & 5.1 \\
\hline
\end{tabular}

The effect of permeate pressure on the net driving force for membrane permeation is particularly significant when the vapor pressure of the feed liquid is low, as in the case of mixtures of low volatility or low temperature feed streams. In such cases, decreasing the permeate pressure will increase the driving force and the permeation rate. However, it is not practical to decrease the permeate pressure indefinitely because the energy costs increase sharply as the permeate pressure decreases. A better approach is to heat the feed stream, thereby raising the vapor pressure of the feed stream and the transmembrane pressure difference.

The separation factor is also a function of the permeate pressure and increases as the permeate pressure decreases as shown in Table 12. At a permeate pressure of $50 \mathrm{torr}$, the ethanol/methyl ethyl ketone separation factor is 3.5 , increasing to 5.1 at a permeate pressure of 10 torr.

The separation factor for ethanol/methyl ethyl ketone is dependent on a number of parameters including the operating pressure ratio, which is the ratio of feed pressure to permeate pressure. The pressure ratio determines the maximum enrichment of a species in the permeate, because permeation ceases once the vapor pressure of the species in the permeate equals the vapor pressure in the feed. Therefore, highly selective membranes must be operated at high pressure ratios to produce high enrichments and good separation. At a permeate pressure of 50 torr, the pressure ratio is 1.9, and the separation factor (3.5) is limited by the pressure ratio. Decreasing the permeate pressure to 10 torr increases the pressure ratio to 9.6 . The separation factor increases to 5.1 once the limitation imposed by the pressure ratio is removed. 


\subsubsection{Feed Composition}

Permeation in polymer membranes proceeds by the permeant sorbing into the polymer phase and diffusing across the membrane. As the affinity of the permeant for the membrane material increases, the sorption of the permeant into the membrane can be large. In such cases the membrane is said to be "swollen" with permeate and the sorption and diffusion characteristics of the membrane change to reflect the swollen state.

Membrane swelling phenomena can be studied by varying the amount of the preferentially sorbed component in the feed stream to affect the level of sorption in the membrane phase. This is illustrated in Table 13 by data from the pervaporation of ethanol/methyl ethyl ketone mixtures with progressively increasing ethanol concentration. Pressure-normalized fluxes of ethanol and methyl ethyl ketone through the membrane are given.

Table 13. The Effect of Feed Ethanol Concentration on the Pervaporation Separation of Ethanol/Methyl Ethyl Ketone Mixtures Using Elvamide ${ }^{\star}$ Film Membrane

Feed Temperature: $55^{\circ} \mathrm{C}$; Permeate Pressure, 10 torr

\begin{tabular}{|c|c|c|c|c|}
\hline \multirow[t]{2}{*}{$\begin{array}{l}\text { Feed ethanol } \\
\quad(w t \%)\end{array}$} & \multirow{2}{*}{$\begin{array}{c}\text { Membrane flux } \\
\left(\mathrm{kg} / \mathrm{m}^{2} \mathrm{~h}\right)\end{array}$} & Ethanol flux & $\begin{array}{l}\text { Methyl ethyl } \\
\text { ketone flux }\end{array}$ & \multirow{2}{*}{$\begin{array}{l}\alpha_{\text {mambres }} \\
\text { Ethanol/methy } \\
\text { ethyl ketone }\end{array}$} \\
\hline & & \multicolumn{2}{|c|}{$\left(\mathrm{cm}^{3}(\mathrm{STP}) / \mathrm{cm}^{2} \mathrm{scmHg}\right)$} & \\
\hline 7.8 & 0.18 & $1.65 \times 10^{4}$ & $3.67 \times 10^{-5}$ & 4.50 \\
\hline 16.2 & 0.38 & $2.67 \times 10^{-4}$ & $6.65 \times 10^{-5}$ & 4.01 \\
\hline 23.0 & 0.54 & $3.46 \times 10^{-4}$ & $8.92 \times 10^{-5}$ & 3.88 \\
\hline 28.0 & 0.68 & $4.16 \times 10^{-4}$ & $1.08 \times 10^{-4}$ & 3.85 \\
\hline
\end{tabular}

As the concentration of ethanol in the feed stream increases, the quantity of ethanol sorbed by the membrane also increases. The data in Table 13 show that the total flux increases as a function of ethanol concentration in the feed. The pressure-normalized flux of ethanol also increases with the feed ethanol concentration. Since the pressure-normalized flux is normalized with respect to the vapor pressure of ethanol in the feed and permeate, it is only a function of the membrane permeability and thickness. Therefore the increase in the pressure-normalized flux must be attributed to membrane swelling.

In Figure 18, the calculated pressure-normalized fluxes of ethanol and methyl ethyl ketone are plotted as a function of ethanol feed concentration. Both fluxes increase linearly with the ethanol concentration, a consequence of the progressive swelling of the membrane. The data can be fitted to straight lines with very good correlation $(r>0.995)$. The intercept represents the permeation rate in the limit of very small ethanol concentrations in the feed, i.e. the membrane is not swollen. The ratio of the normalized fluxes at this limiting condition gives the ideal selectivity of the membrane, 7.3 for ethanol/methyl ethyl ketone. If we extrapolate the straight lines to higher concentrations, we obtain the limiting selectivity of the fully swollen membrane, 3.5 for ethanol/methyl ethyl ketone. Figure 19 shows the membrane selectivity and flux as a function of feed ethanol concentration. 


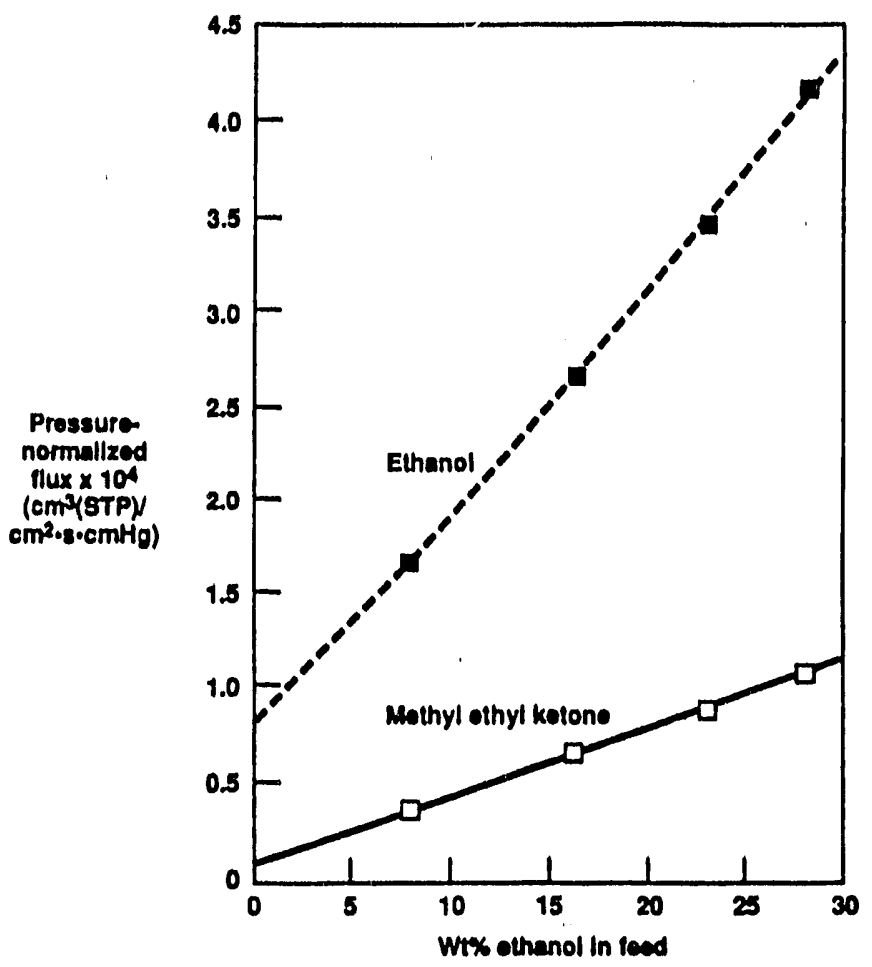

zocap

Figure 18. Pressure-normalized fluxes of ethanol and methyl ethyl ketone through polyamide membranes at $55^{\circ} \mathrm{C}$.

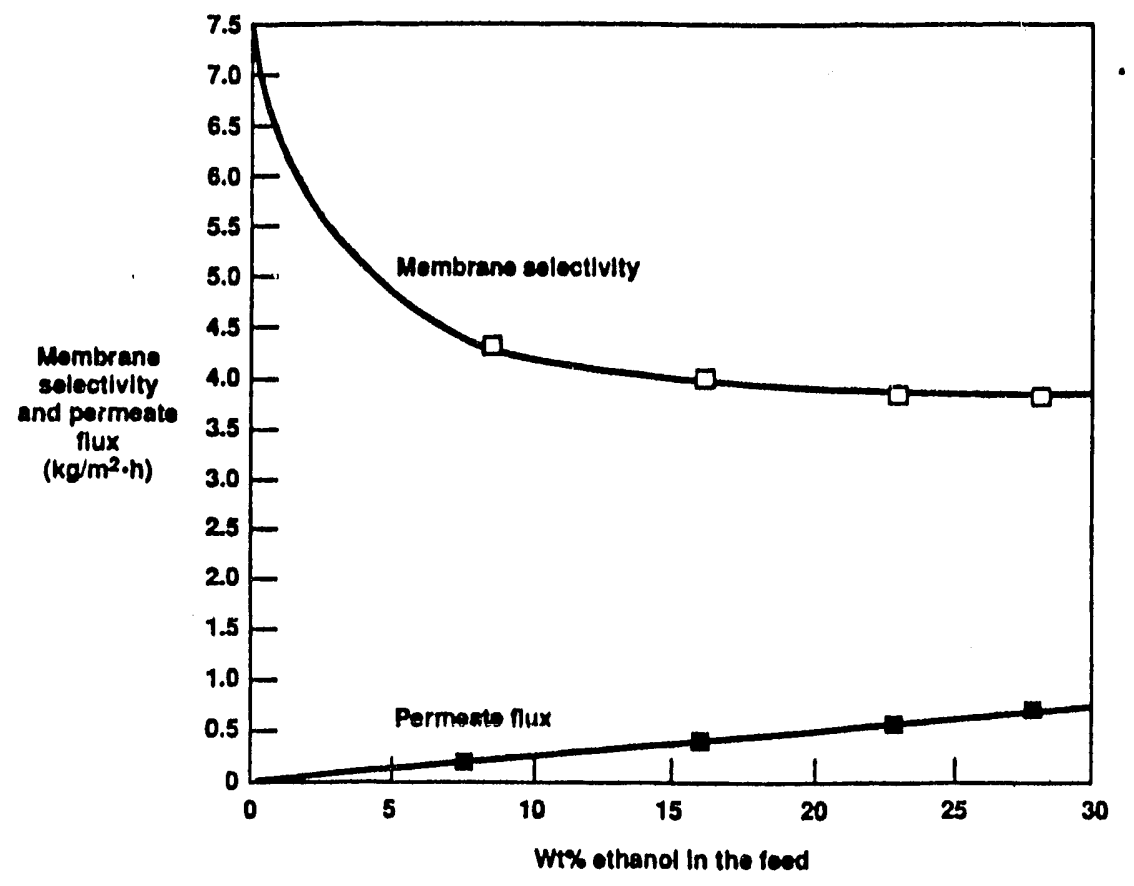

227.GPP

Figure 19. Membrane selectivity and total permeate flux for the permeation of ethanol-methyl ethyl ketone mixtures through polyamide membranes at $55^{\circ} \mathrm{C}$. 
The predicted fluxes of ethanol and methyl ethyl ketone are shown along with the experimental observations in Figure 20. Note that the flux of methyl ethyl ketone initially increases with increasing levels of ethanol in the feed because the membrane is becoming more swollen and consequently more permeable. However, as the methyl ethyl ketone in the feed decreases, the driving force for methyl ethyl ketone permeation decreases and the flux decays. Ethanol is a good solvent for Elvamide, which is the reason for the large amount of swelling observed. At high concentrations the membrane will swell to a gel-like state and eventually dissolve. Therefore the extrapolation to high ethanol concentrations is to illustrate the capabilities of our model of pervaporation and is not intended to be a realistic prediction of membrane behavior for this specific case.

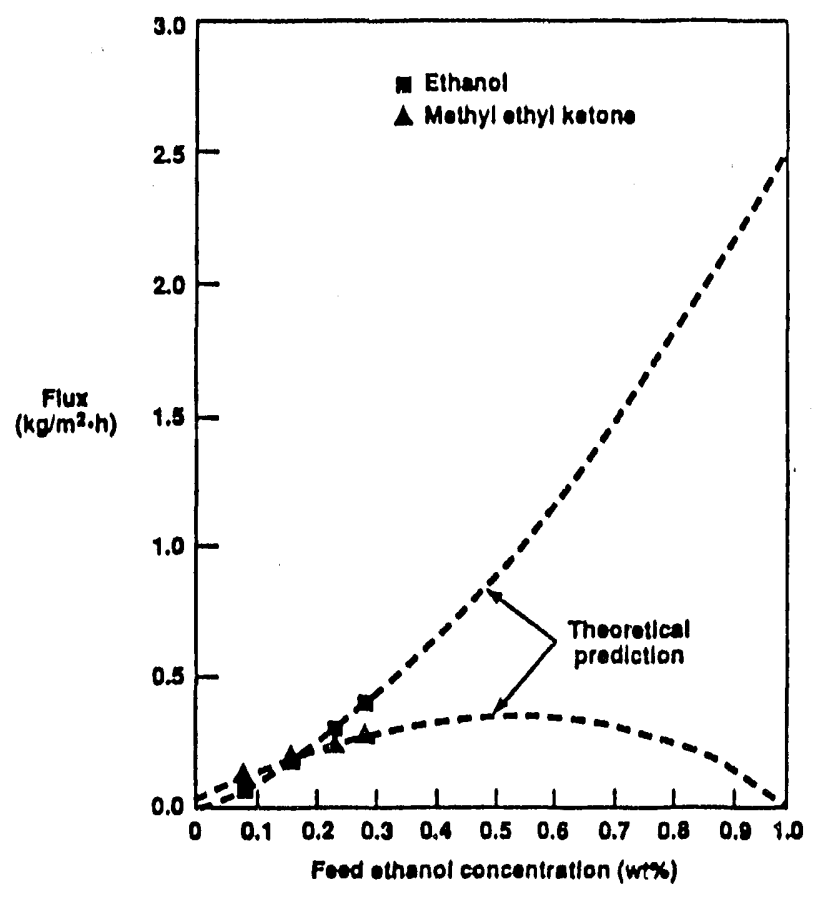

mane

Figure 20. Ethanol and methyl ethyl ketone flux through polyamide membranes at $55^{\circ} \mathrm{C}$.

Figure 21 presents the extrapolated pervaporation separation characteristics for the ethanol/methyl ethyl ketone separation, superimposed on the vapor liquid equilibrium data. Based on our prediction, the pervaporation system can be operated at any feed concentration and will not result in an azeotrope. 


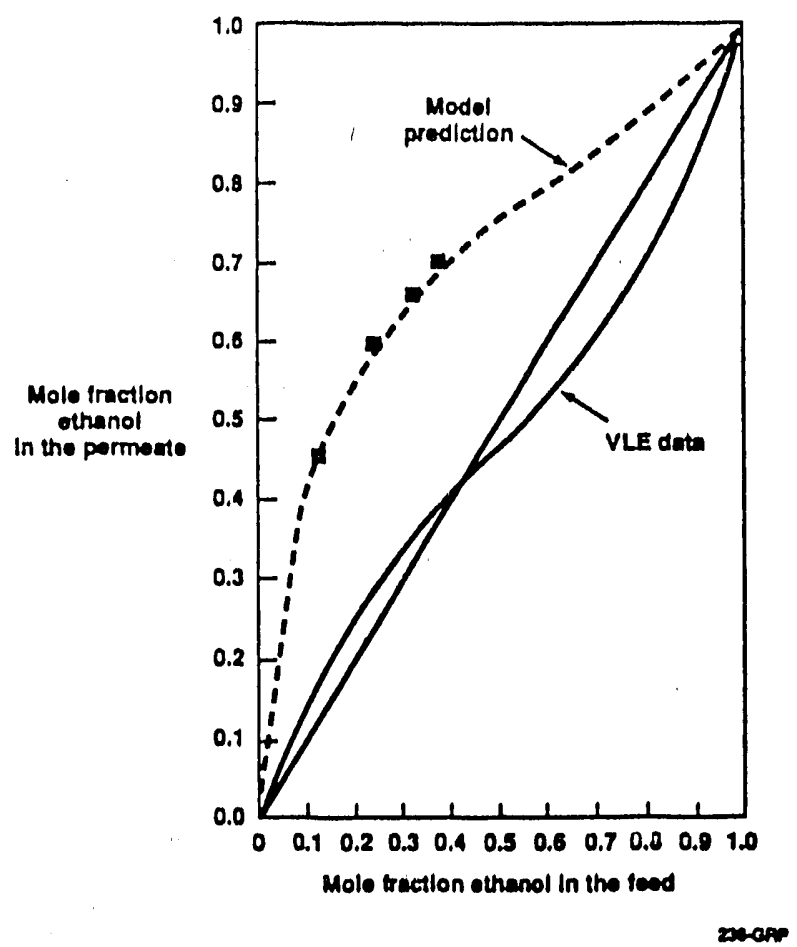

Figure 21. Experimental data and theoretical prediction for the pervaporation of ethanol/methyl ethyl ketone mixtures through polyamide membranes at $55^{\circ} \mathrm{C}$.

\subsubsection{Feed Temperature}

The permeation of a species through a membrane is governed by the amount of sorption of the species in the membrane and the rate of diffusion of the sorbed permeant. Generally, sorption decreases with increasing temperature while the diffusion coefficient increases with temperature. Therefore, the permeability coefficient may increase or decrease with temperature depending on the relative importance of sorption and diffusion phenomena as rate-controlling processes. The preferentially permeating species typically has a large sorption coefficient for the membrane material. Increasing the feed temperature will decrease the permeability of this species because the decrease in the sorption coefficient will be greater than the increase in the diffusion coefficient. On the other hand, the less permeable component of the feed generally has a low affinity for the membrane material and hence a low sorption coefficient. The increase in temperature will produce a greater increase in the diffusion coefficient and a small decrease in the sorption coefficient. Hence the permeability of this species will increase as the temperature increases. The net effect is a decrease in membrane selectivity as the feed temperature increases. This trend is illustrated in Table 14 for the ethanol/methyl ethyl ketone and toluene/methyl cyclohexane mixtures. 
Table 14. The Effect of the Feed Temperature on the Membrane Flux

\begin{tabular}{|c|c|c|c|c|}
\hline \multirow{2}{*}{$\begin{array}{c}\text { Temperature } \\
\left({ }^{\circ} \mathrm{C}\right)\end{array}$} & \multirow{2}{*}{$\begin{array}{l}\text { Membrane flux } \\
\qquad\left(\mathrm{kg} / \mathrm{m}^{2} \mathrm{~h}\right)\end{array}$} & \multicolumn{2}{|c|}{$\begin{array}{l}\text { Pressure - normalized flux } \\
\left(\mathrm{cm}^{3}(\mathrm{STP}) / \mathrm{cm}^{2} \mathrm{scmHg}\right)\end{array}$} & \multirow{2}{*}{$\begin{array}{c}\text { Membrane } \\
\text { selectivity } \\
\text { (A/B) }\end{array}$} \\
\hline & & A & B & \\
\hline \multicolumn{5}{|c|}{ Case I. Ethanol (A)/methyl ethyl ketone (B) separation using Elvamide ${ }^{\oplus}$ film } \\
\hline 25 & 0.06 & $3.53 \times 10^{-4}$ & $3.92 \times 10^{-5}$ & 9.0 \\
\hline 55 & 0.18 & $1.65 \times 10^{-4}$ & $3.67 \times 10^{-5}$ & 4.5 \\
\hline \multicolumn{5}{|c|}{ Case II. Toluene (A)/methyl cyclohexane (B) separation using a Pebax ${ }^{\star}$ film } \\
\hline 30 & 0.22 & $7.84 \times 10^{-4}$ & $6.56 \times 10^{-5}$ & 12 \\
\hline 60 & 0.92 & $7.41 \times 10^{-4}$ & $9.40 \times 10^{-5}$ & 7.9 \\
\hline
\end{tabular}

The normalized ethanol flux through an Elvamide film decreases by $50 \%$ as the temperature is increased from 25 to $55^{\circ} \mathrm{C}$. The flux of methyl ethyl ketone, however, decreases only slightly $(\sim 10 \%)$ and consequently the membrane selectivity for ethanol over methyl ethyl ketone is halved, from 9 to 4.5.

In the toluene/methyl cyclohexane separation, the toluene fiux through a Pebax 4011 film decreases but the methyl cyclohexane flux increases as the temperature is raised from 30 to $60^{\circ} \mathrm{C}$. The membrane selectivity decreases from 12 to 8 .

The data for the ethyl acetate/water separation support the observed trend of selectivity declining with temperature because of the decrease in the flux of the more permeable component. The flux of water, the more permeable component, decreases with temperature as shown in Figure 22. The scatter in the ethyl acetate flux measurements obscure any trend, but the flux appears to be either increasing or remaining constant as the temperature is raised. The calculated membrane selectivity, plotted versus temperature in Figure 23, reflects the scatter of the ethyl acetate flux measurements, but a trend of decreasing membrane selectivity with increasing temperature is clearly evident.

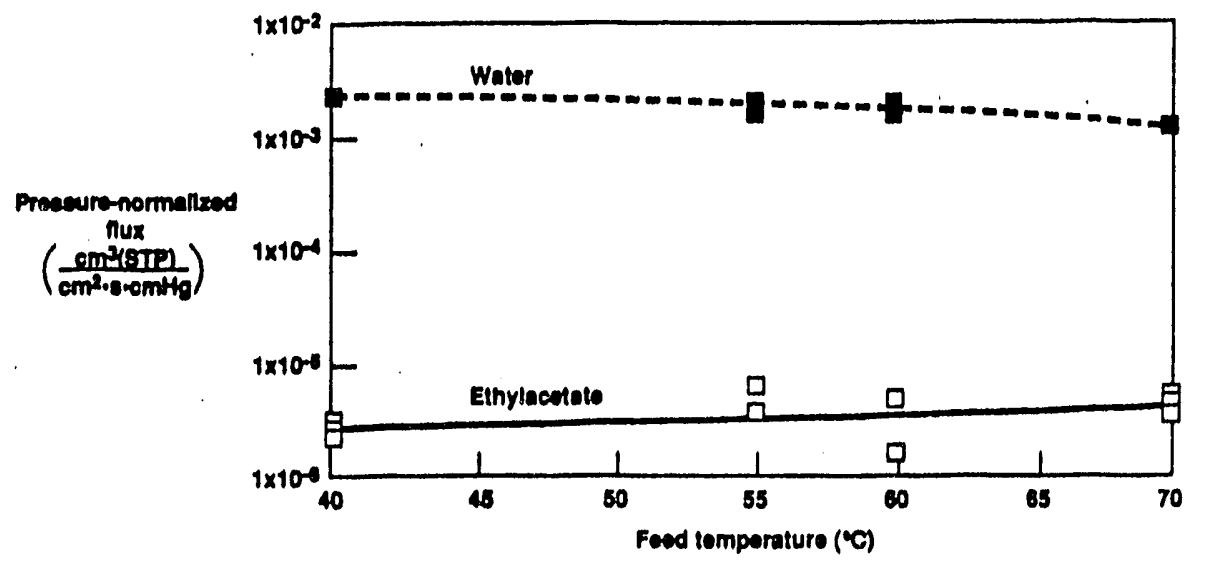

2000\%

Figure 22. Pressure-normalized flux of water and ethyl acetate through polyamide membranes. 


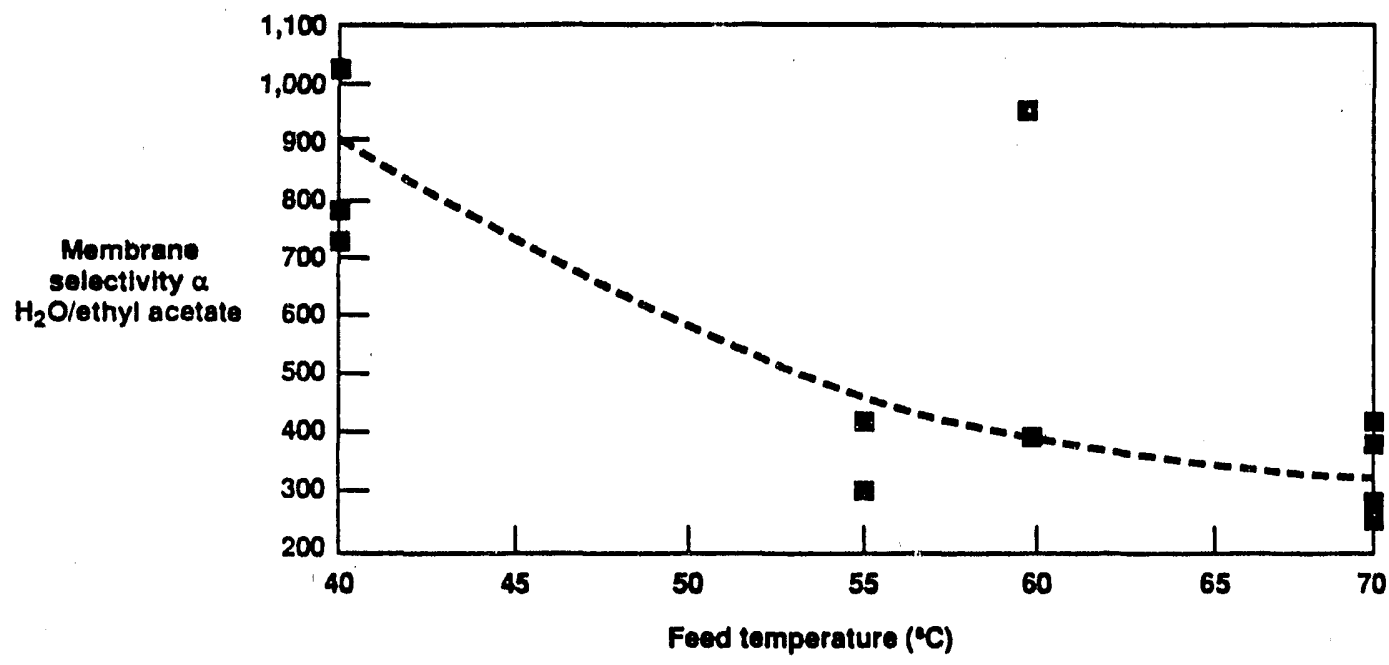

229-GPP

Figure 23. Calculated membrane selectivity for the pervaporation of ethyl acetate/water mixtures.

Our results indicate that increasing the feed temperature decreases the pressure-normalized flux of the most permeable species, resulting in a less efficient separation. However, the higher feed vapor pressure at the elevated temperature increases the driving force for permeation through the membrane, increasing the permeate flow rate. Therefore in selecting an operating temperature, higher membrane productivity must be balanced with lower separation efficiency.

\section{TECHNICAL ANALYSIS}

We performed a preliminary technical analysis to determine the feasibility of using the Elvamide composite membranes developed in this program to break the ethanol/methyl ethyl ketone azeotrope. The schematic diagram for such a process is shown in Figure 24. An 80:20 methyl ethyl ketone:ethanol feed stream is fed to the first distillation column and pure methyl ethyl ketone is obtained as the bottom product. The top product is the ethanol/methyl ethyl ketone azeotrope. This stream is sent to a membrane pervaporation unit which returns a methyl ethyl ketone-rich residue stream to the first distillation column. The ethanol-rich permeate stream is fed to a second distillation column which produces pure ethanol as a bottom product. The top product is the ethanol/methyl ethyl ketone azeotrope which is recycled to the pervaporation system. In practice the distillation columns would be operated close to the azeotrope to avoid increasing the number of stages required. At $55^{\circ} \mathrm{C}$, the azeotrope forms at a concentration of $29 \mathrm{wt} \%$ ethanol. For this example, we have considered a feed stream to the membrane containing $35 \%$ ethanol that must be reduced to $25 \%$ ethanol by pervaporation to circumvent formation of the azeotrope. The pervaporation system design parameters are as follows: 


\section{Feed stream}

Flow rate:

Composition:

Temperature:

Residue stream

Composition:
$100 \mathrm{~kg} / \mathrm{h}$

35 wt \% ethanol, 65 wt\% methyl ethyl ketone $55^{\circ} \mathrm{C}$

25 wt\% ethanol

75 wt\% methyl ethyl ketone

Membrane: Polyarnide composite membrane

Pressure-normalized ethanol flux

Pressure-normalized methyl ethyl ketone flux
$4.3 \times 10^{-4} \mathrm{~cm}^{3}(\mathrm{STP}) / \mathrm{cm}^{2} \cdot \mathrm{s} \cdot \mathrm{cmHg}$

$1.1 \times 10^{-4} \mathrm{~cm}^{3}(\mathrm{STP}) / \mathrm{cm}^{2} \cdot \mathrm{s} \cdot \mathrm{cmHg}$

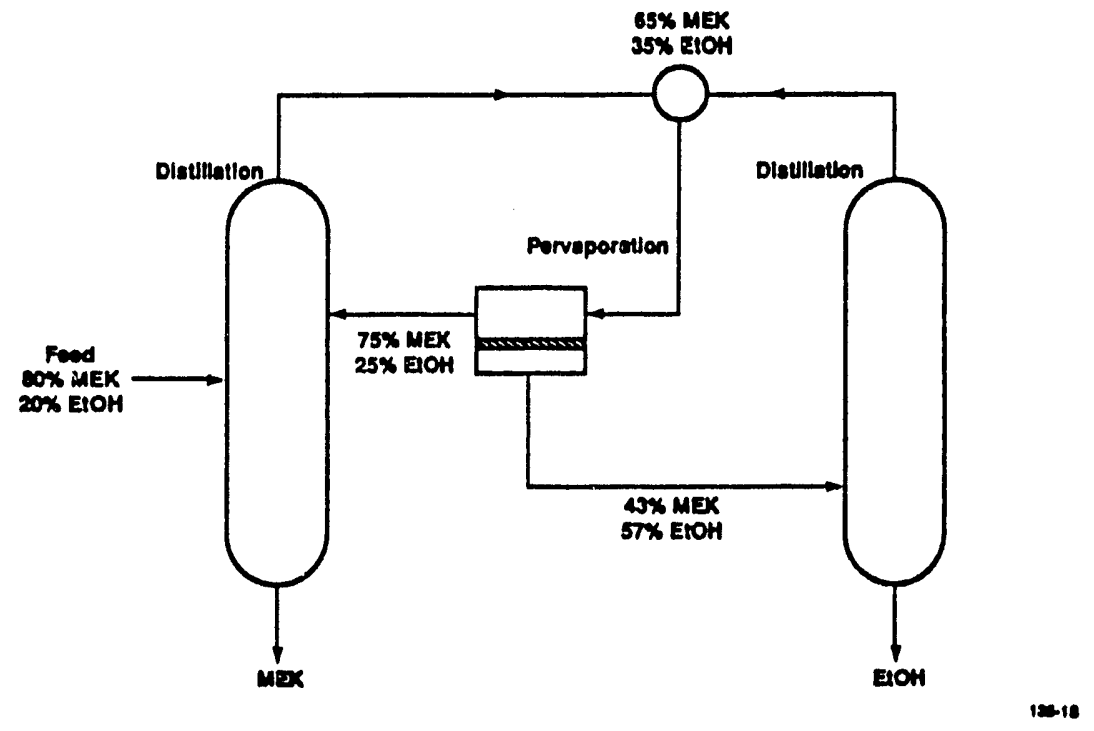

Figure 24. Process scheme for a distillation-pervaporation hybrid system used to separate ethanol (EtOH)/methyl ethyl ketone (MEK) mixtures. (The system forms a 71 wt\% methyl ethyl ketone $/ 29$ wt\% ethanol azeotrope at $55^{\circ} \mathrm{C}$.)

The influence of the permeate pressure as the design parameter on the permeate composition, membrane area requirement, stage-cut, condenser temperature and cooling energy requirements are shown in Table 15 for permeate pressures of 100,50 and 10 torr. 
Table 15. Membrane Size and Energy Requirement for the Pervaporation System

\begin{tabular}{|c|c|c|c|}
\hline & \multicolumn{3}{|c|}{ Permeate pressure } \\
\hline & 100 torr & 50 torr & 10 tort \\
\hline $\begin{array}{l}\text { Permeate concentration } \\
\text { (wt\% ethanol) }\end{array}$ & 51.7 & 56.7 & 60.3 \\
\hline $\begin{array}{l}\text { Ethanol flux } \\
\left(\mathrm{kg} / \mathrm{m}^{2} \mathrm{~h}\right)\end{array}$ & 0.25 & 0.35 & 0.43 \\
\hline $\begin{array}{l}\text { Methyl ethyl ketone flux } \\
\left(\mathrm{kg} / \mathrm{m}^{2} \mathrm{~h}\right)\end{array}$ & 0.24 & 0.26 & 0.28 \\
\hline $\begin{array}{l}\text { Permeate flow rate } \\
(\mathrm{kg} / \mathrm{h})\end{array}$ & 37 & 32 & 28 \\
\hline $\begin{array}{l}\text { Membrane area } \\
\left(\mathrm{m}^{2}\right)\end{array}$ & 76 & 52 & 40 \\
\hline $\begin{array}{l}\text { Condenser temperature } \\
\left({ }^{\circ} \mathrm{C}\right)\end{array}$ & 7.7 & -6.3 & -30.7 \\
\hline $\begin{array}{l}\text { Condenser load: } \\
\text { Cooling (Btu/h) } \\
\text { Condensation (Btu/h) } \\
\text { Total }(B t u / h)\end{array}$ & $\begin{array}{l}2,800 \\
21,400 \\
24,200 \\
\end{array}$ & $\begin{array}{c}3,000 \\
18,700 \\
21,700 \\
\end{array}$ & $\begin{array}{l}3,700 \\
17,100 \\
20,800 \\
\end{array}$ \\
\hline
\end{tabular}

The system size is determined by the membrane area requirement and the cooling energy requirement. As the permeate pressure decreases from 100 to 10 torr the membrane area required decreases by about $50 \%$. This is because of the better separation obtained at higher pressure ratios: both the flux and separation factor are greater at the lower permeate pressure. The permeate stream is $20 \%$ smaller and more concentrated in ethanol. The cooling energy requirements also decrease as the permeate pressure decreases due to the smaller volume of permeate that must be condensed. Although the permeate is being condensed at a much lower temperature, $-31^{\circ} \mathrm{C}$ at a permeate pressure of 10 torr, compared with $8^{\circ} \mathrm{C}$ at a permeate pressure of 100 torr, the cooling energy requirements are dominated by the condensation of the permeate vapor. Cooling the permeate from the feed temperature down to the condensation temperature represents less than $20 \%$ of the total cooling load. Therefore, operating at a low condenser temperature does not appear to be a disadvantage when sizing the system. Operating at a permeate pressure of 10 torr requires the smallest pervaporation system. However, the size of the refrigeration system is not included in this estimate.

The energy requirements of pervaporation are dominated by the heating and cooling requirements for the feed and permeate streams, respectively. Part of the feed solution changes from the liquid to the vapor phase during the pervap' ation process and the latent heat of evaporation must be supplied to the feed stream. The permeate stream leaving the membrane is a vapor that must be condensed; cooling is necessary to remove the heat of condensation. It seems possible that the two processes could be coupled using a heat engine so that the net energy input into the system would be small. However, unlike distillation, membrane processes are non-equilibrium processes and energy is lost in the permeation step. 
We pay for this energy loss by the need to condense the permeate stream at low pressures, requiring low condenser temperatures. This is where the costs of pervaporation begin to emerge. Although operating the membrane system at 100 torr requires a larger membrane area, the permeate is condensed at approximately $8^{\circ} \mathrm{C}$. Process cooling water, coupled with a small refrigeration unit, are sufficient for this task. However, if we opt for the smaller membrane system operating $10 \mathrm{torr}$, the permeate is now condensed at $-31^{\circ} \mathrm{C}$, necessitating a low temperature refrigeration system. The size and cost of the refrigeration system will dominate the total cost of the unit and may be even greater than that of the membrane system, piping and controls. Therefore, if we include the cost of the cooling/refrigeration system, it becomes uneconomical to operate at low permeate pressures.

The permeate-side vacuum is generated by condensing the permeate stream, which contains a minimal non-condensable component. A vacuum pump is used to remove the non-condensables and prevent accumulation but, due to the size of the stream, the energy requirements are low.

The high cost of condensation at low permeate pressures is the penalty for not using mechanical means for generating the permeate-side vacuum. One way to reduce the energy cost is to generate the permeate vacuum partially by mechanical means and to use condensation to complete the process. A Roots blower mounted in front of the condenser could be used to raise the permeate pressure to a more favorable value for condensation. The optimum distribution of the load for generating the permeate vacuum would vary with the composition of the perivaste streams. In dehydration the permeate is mostly water, which can be condensed relatively easily; no mechanical means would be necessary. However, for the case of very volatile permeants, such as methylene chloride, a substantial amount of the energy requirement may be used to elevate the permeate pressure by mechanical means before condensation; the energy requirement for the Roots blower would dominate the total cooling energy requirement.

One important conclusion to be drawn from this analysis is that the overall separation factor will be pressure ratio limited. Membranes have sufficient selectivity for most organic/organic separations. Heating the feed stream or using mechanical means to generate the permeate vacuum will increase the pressure ratio and remove the limitation on the separation. The key to energy-efficient pervaporation systems is further study of the operating parameters. This would result in innovative process designs.

\section{CONCLUSIONS}

In this program we developed composite membranes for separating organic-organic and organicwater azeotropes and close boiling mixtures by pervaporation. Three mixtures were chosen for representative separations and the performance of suitable membranes was studied up to the level of pilotscale modules. The results indicate that pervaporation is a viable process for separating azeotropes and close-boiling mixtures. We were able to break the ethanol/methyl ethyl ketone azeotrope using polyamide membranes. Good separations were obtained with toluene/methyl cyclohexane and ethyl acetate/water mixtures. 
Permeation through pervaporation membranes is dominated by preferential sorption. Based on this factor, we developed a method for rapidly screening candidate polymers for a separation. In all of our separations we observed that the separation factor decreased with increasing concentration of the most permeable component in the feed stream. We attributed this loss of selectivity to sorption-induced swelling of the membranes. By introducing a concentration-dependent permeability into our model for pervaporation, we were able to demonstrate an excellent fit between the model prediction and experimental observations.

A preliminary technical analysis of a pervaporation/distillation hybrid system to separate an azeotropic mixture was prepared. Our analysis showed that decreasing the permeate pressure in the pervaporation unit would increase the throughput (flux) and separation achieved by the pervaporation unit.

We did not address all of the module development issues during this program. One of the most important issues is the choice of membrane glue. Although we tested a number of glues and identified amine-cured epoxies as having the best chemical resistance, module performance was less than that predicted from membrane stamp results. In most cases there was no catastrophic failure, suggesting that the modules, as fabricated, were defect-free. The decrease in performance was attributed to swelling of the glue and poor glue line resistance, which may have resulted in erosion and pinhole formation in the glue lines. A more extensive study of the chemical resistance of glues, coupled with a long-term module stability test, is required to address this issue.

Calculations based on our experimental data suggest that the energy efficiency of pervaporation for organic-organic separation is linked to operating conditions such as the feed temperature and the permeate pressure. In this study we focused on membrane and module development issues; more work is necessary to identify the optimal operating parameters for a pervaporation system. Such a study will guide the design and development of energy-efficient pervaporation systems which will offer a competitive challenge to extractive distillation and other azeotrope separation methods. Analysis of the economics of specific industrial distillation operations will revea! processes for which pervaporation would be a competitive alternative and will irentify the applications on which to concentrate developmental effort. 

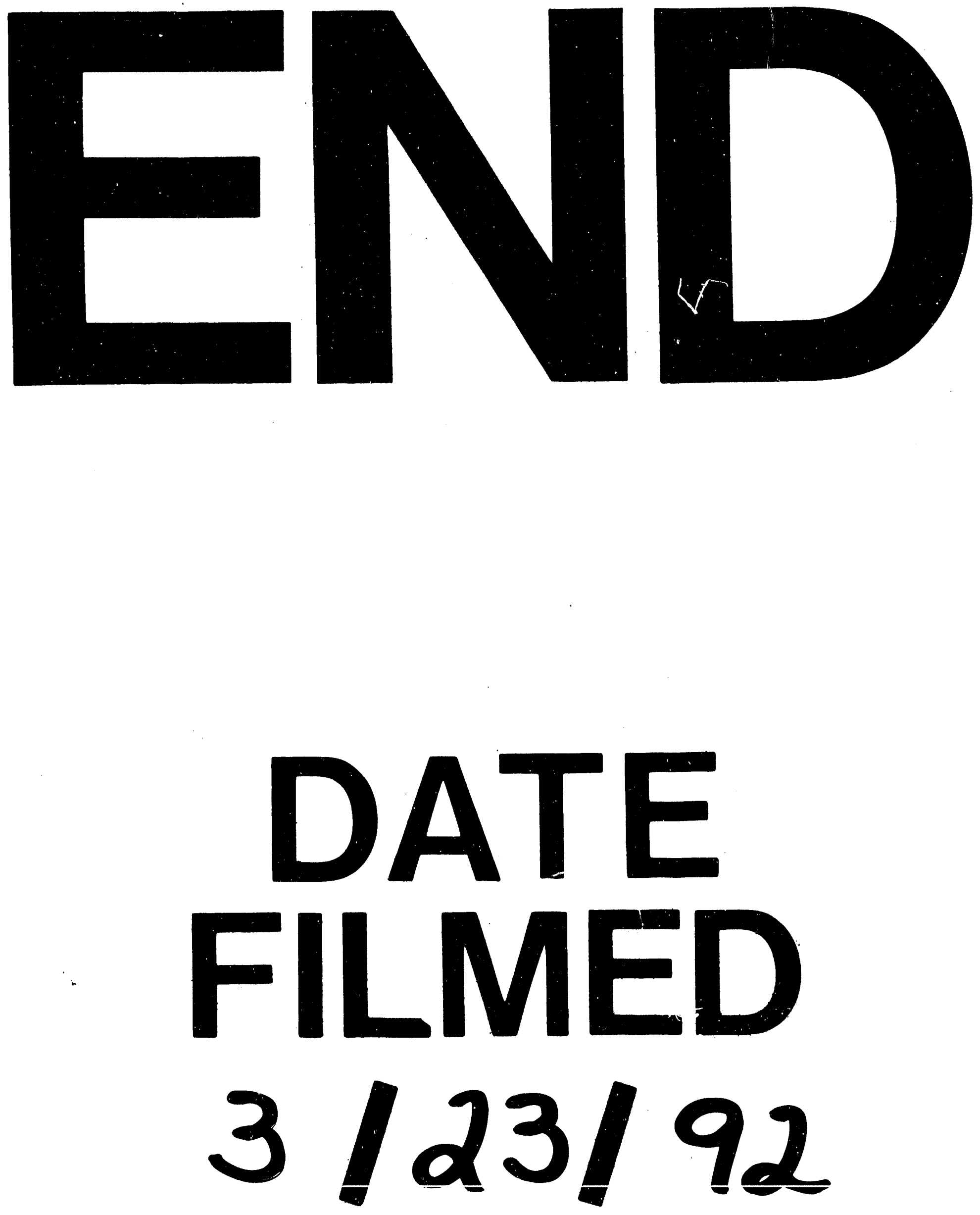

1 


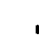

